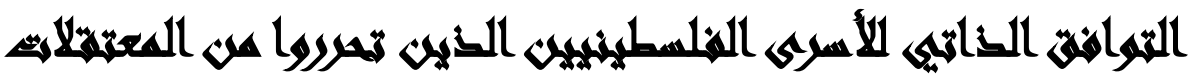

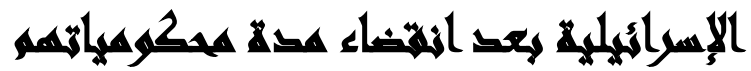

\section{[9]}

معين عينساوي(')- أحمد مصطفى العتيق(ץ)-- مصطفى ابراهيم عوض(ץ)(

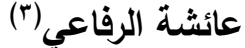

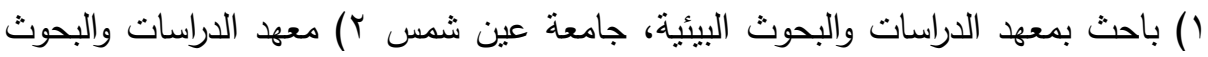

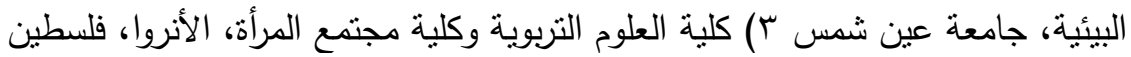

\section{المسترلت}

نهدف في هذا البحث التعرف إلى آليات التوافق الذاتي لدى الأسرى الفلسطينيين

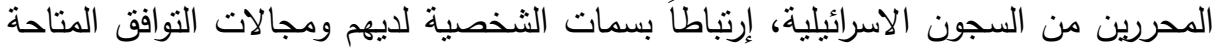

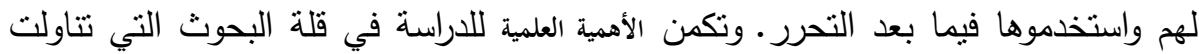

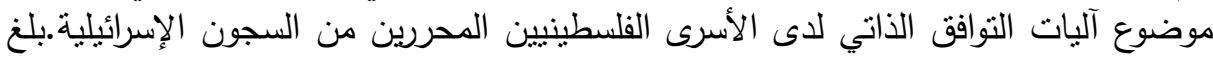
عدد الإعتقالات التي تعرض لها المواطنون الفلسطينيون منذ إحتلال فلسطين عام (197V)

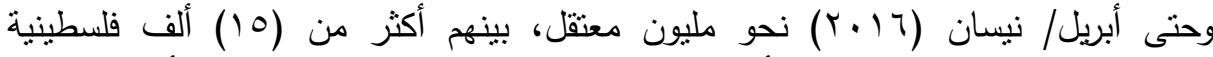

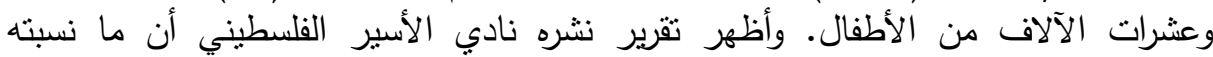

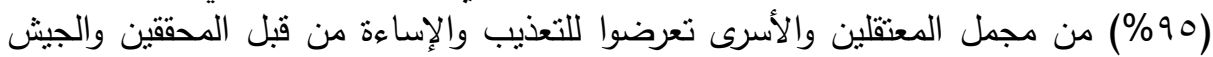

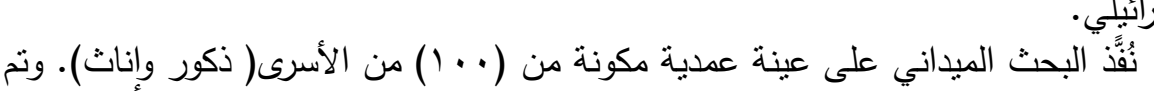
الإسرائيلي.

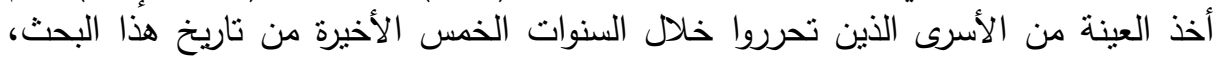

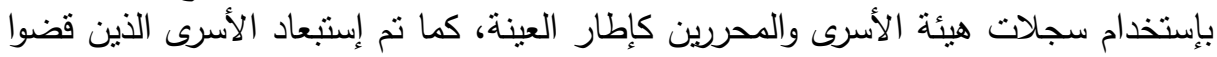

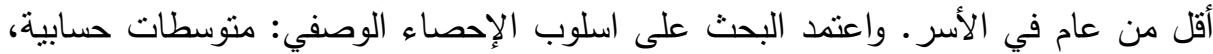

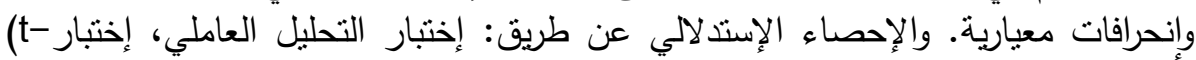
test) كرونباخ ألفا .

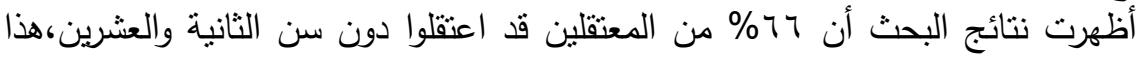

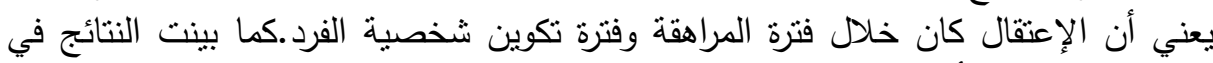

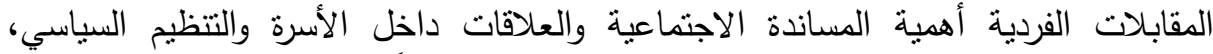

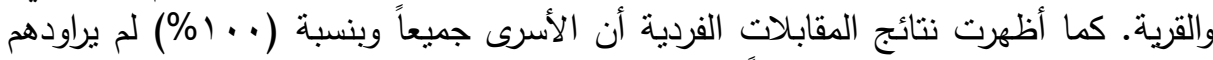

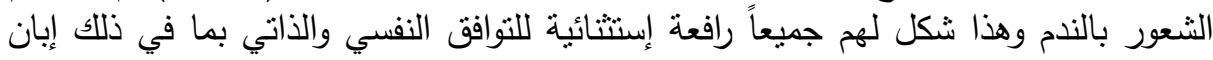

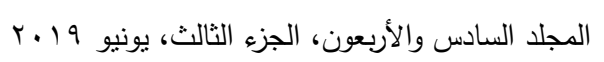




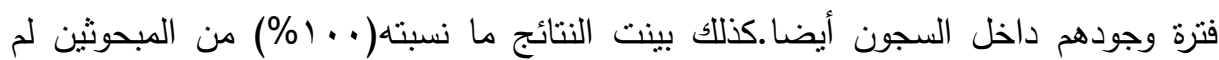

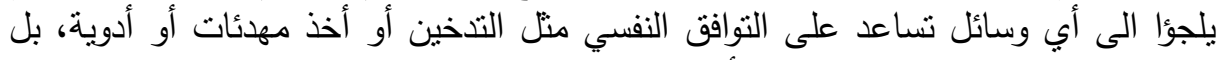
توجهوا للبحث عن شريكة حياة وبناء أسرة وتعليم وهو ما شكل توافق ذاتي لاتي لديهم.

\section{xaradl}

إن الإغتراب داخل السجون ولفترات طويلة قد يصل فيها الإعتقال إلى أكثر من ثلاثين

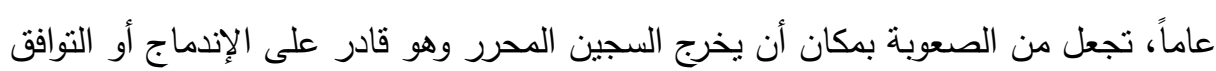
والتعايش النفسي والإجتماعي مع مجتمعه، سواء داخل الأسرة أو المجتمع، مما يتطلب آليات

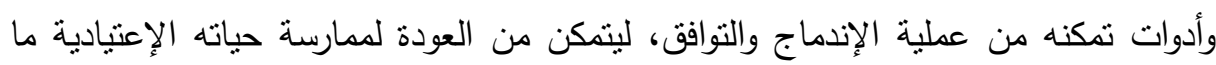

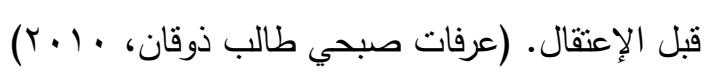

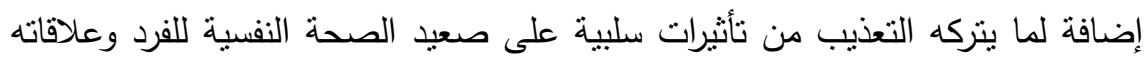

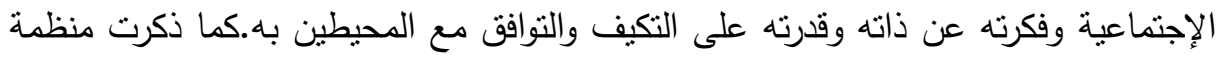

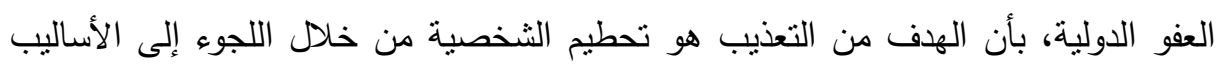

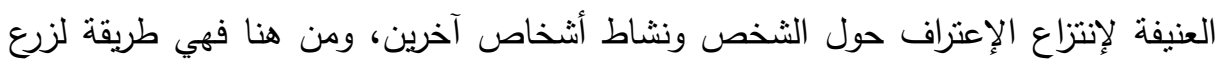

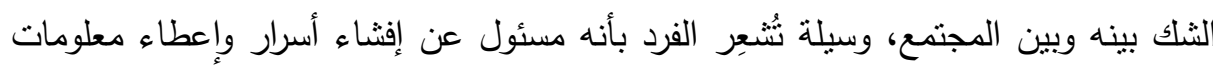

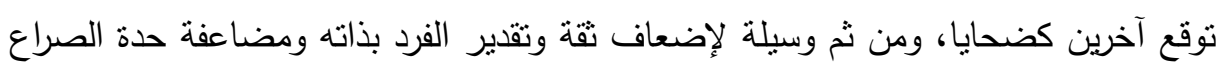

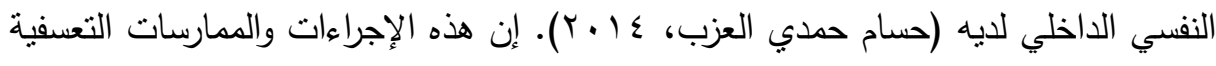

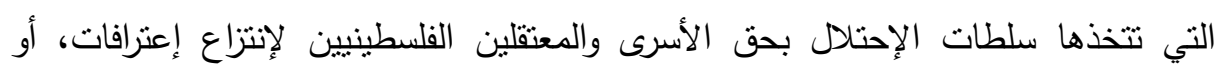

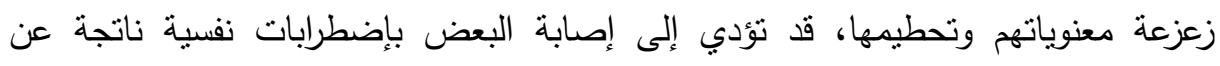

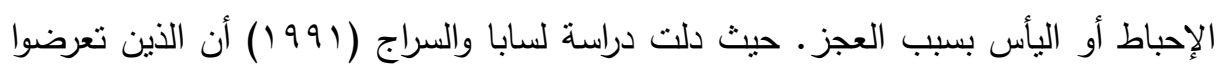
للضرب أثناء الإعتقال كانوا سريعي الغضب ولا يستطيعون الإنتظار، وذلك لأن الإنتظار كان

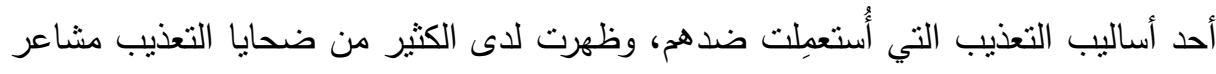

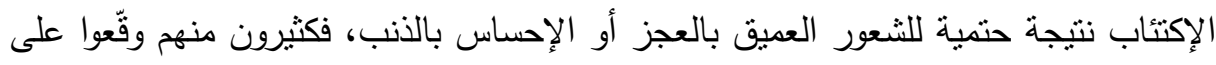

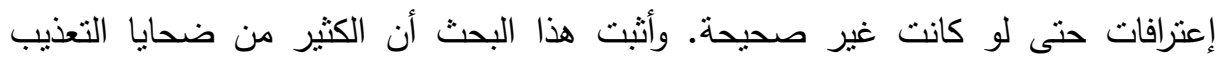
والترويع يحتاجون إلى العلاج النفسي بعد خروجهم من السجون والمعتقلات. (سابا، رغدة،

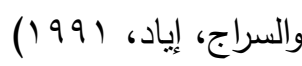




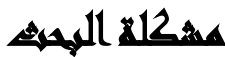

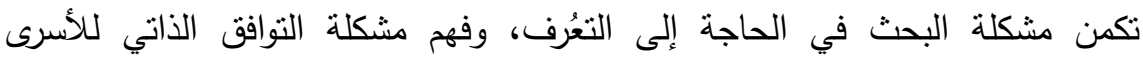
الححرين من السجون الإسرائيلية والآليات الستخذمة للتوافق الذاني لهؤلاء الأسرى. كما تكمن

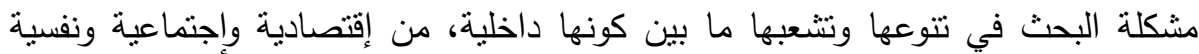

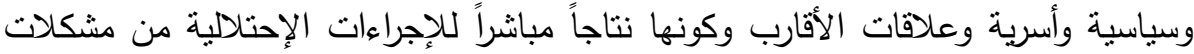

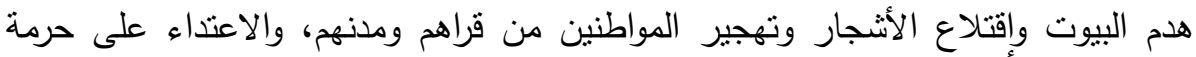

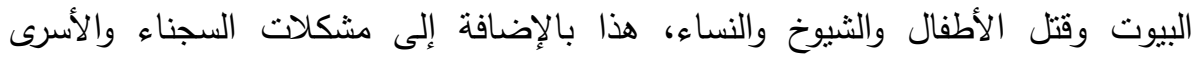

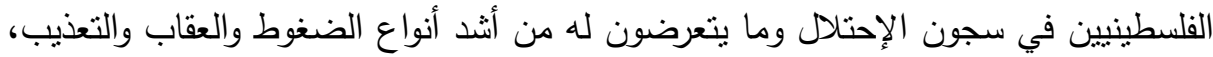

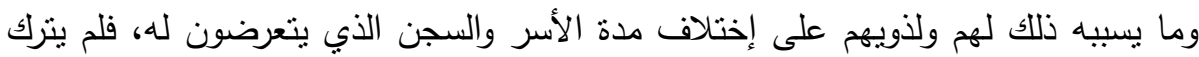
الإحتلال مشكلة وكارثة إلا وتسبب بها للثعب الفلسطيني. وهو ما جاء في دراسة علاونة (rا.بr) في دراسته تحت عنوان " الآثار السياسية والإقتصادية والإجتماعية على الأسرى الححرين من سجون الإحتلال الصهيوني في الإني فلسطين". ودراسة حميدة (r Y r) تحت عنوان " العلاقة بين أحداث الحياة الضاغطة ومستوى

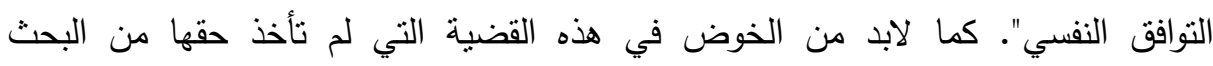

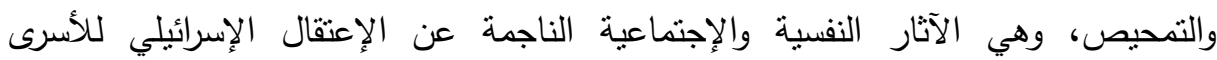

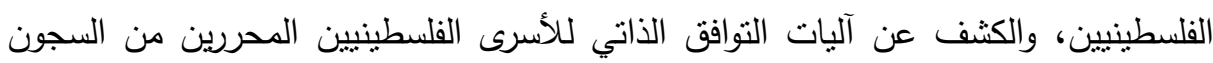

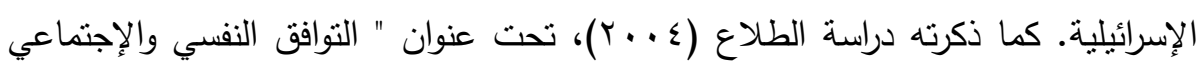
وعلاقته بالإنتماء لاى الأسرى المحررين من السجون الإسرائيلية". 


\section{تمساولاهث المهمث}

يتضمن البحث تساؤل رئيسي: " ما هي آليات التوافق والتعايش النفسي والإجتماعي للأسرى الفلسطينيين المحرين من السجون الإسرائيلية" ؟

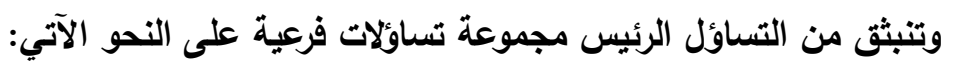

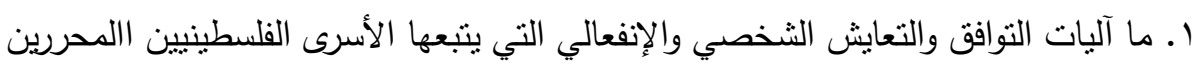

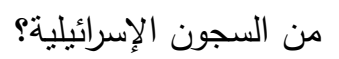
r. ما آليات التوافق والتعابش الصحي (الجسدي) التي يتبعها الأسرى الفلسطينيين المحرين

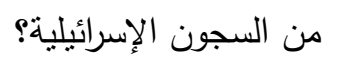
r. ما آليات التوافق والتعايش والنفس إجتماعي التي يتبعها الأسرى الفلسطينيين المحررين من

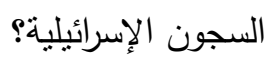

ع. ما آليات التوافق والتعايش الخاصة بالإندماج المجتمعي التي يتبعها الأسرى الفلسطينيين

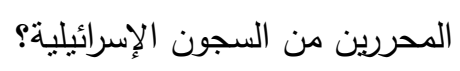

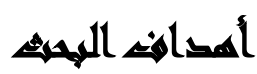

الهدف العام للبحث: التعرف إلى "آليات الثوافق الذاني لاى الأسرى الفلسطينيين الدحرين

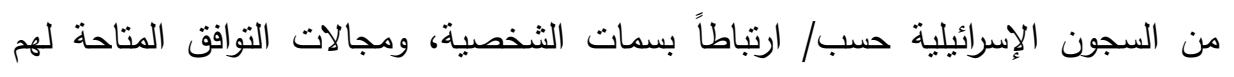

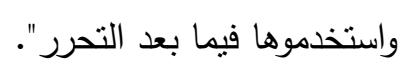

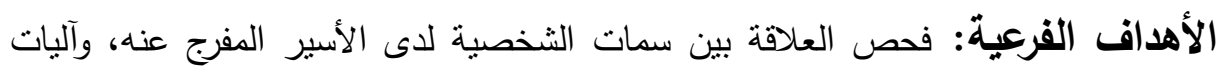

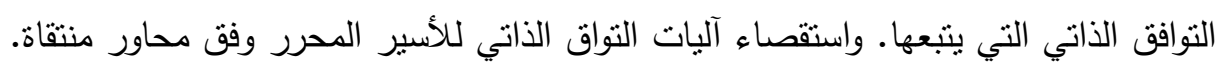

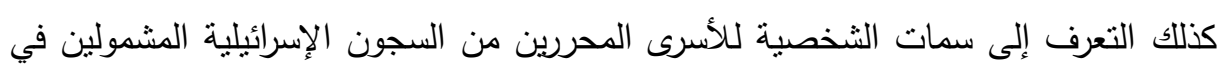

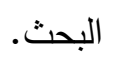




\section{أهمية المهيث}

الأهمية العلمية: قلة البحوث التي تتاولت موضوع آليات التوافق الذاتي لدى الأسرى الفلسطينيين الدحرين من السجون الإسرائيلية (في حدود إطلاع الباحث). والحاجة الى اثراء الجانب النظري للبحوث التي تتاولت آليات التوافق الذاتي لدى الاسرى الفلسطينيين الدحررين

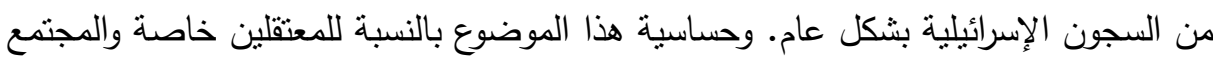

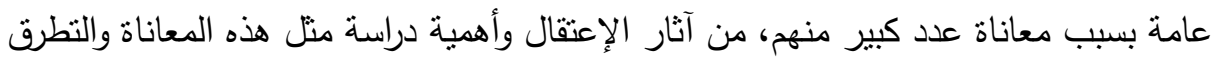
لها بشكل علمي. الأهمية العملية (التطبيقية): تفيد صناع القرار في التعرف على آليات التوافق الذاتي

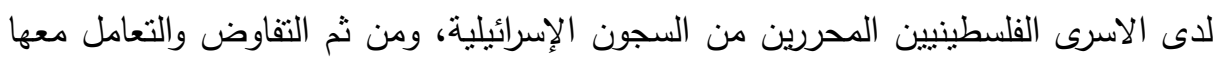
بشكل دقيق. وتساهم في وضع خطط من شأنها تيسيير عملية دمج الأسرى في برامج نؤهلهم الإنسرانه الإنخراط في المجتمع تمكنهم من ان يكونوا افرادا منتجين.

\section{مجالاهي المهميش}

المجال الجغرافي: تم تطبيق البحث في الضفة الغربية كونها تضم العدد الأكبر من الأسرى

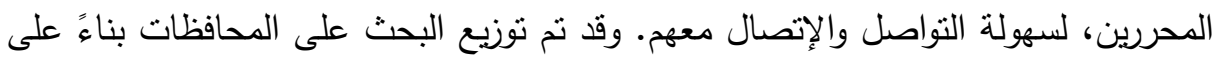

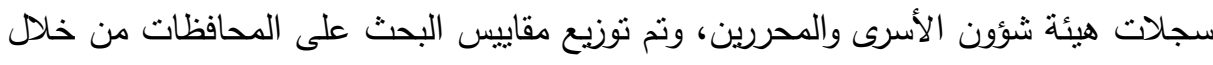
التنسيق والتواصل مع مكاتب هيئة شؤون الأسرى والمحررين. المجال البشري: نم تطبيق هذا البحث على عينة من الأسرى الفلسطينيين (ذكور وإناث) الذين قضوا فترات زمنية مختلفة في السجون الإسرائيلية، وتتطبق عليهم مواصفات وشروط الاندي

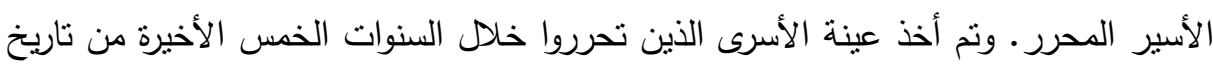

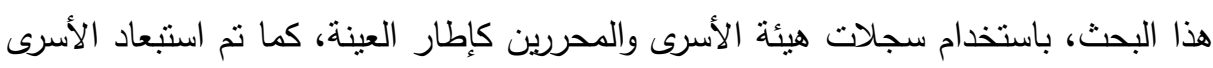
الذين قضوا أقل من عام في الأسر ، إذ بلغت حجم العينة ( . . 1 ) أسير ما بين ذكور وإناث.

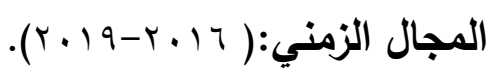




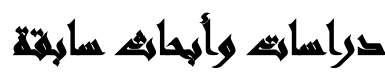

1) دراسة أبو هين (1 ( . ب): تحت عنوان "تقدير الذات وعلاقته بالتوافق النفسي الإجتماعي لاى الشباب الفلسطيني المشارك في إنتفاضه الأقصى. وهدف البحث إلى التعرف على مسنوى التوافق النفسي الإجتماعي وتقدير الذات لاى عينة من الثباب

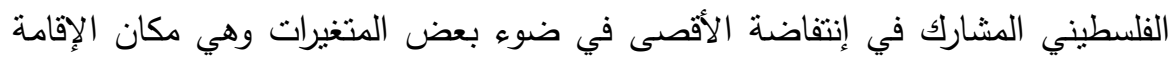

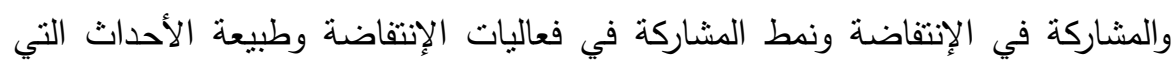
يتعرض لها الثباب. وقد أجريت البحث على ل .0 شخص من الإكور الذين شاركوا في الإنتفاضة بإستخدام إختبار تقدير الذات وإختبار التوافق النفسي الإجنماعي، وإستخدم الباحث إختبار (ت) كأسلوب إحصائي للوصول للنتائج.

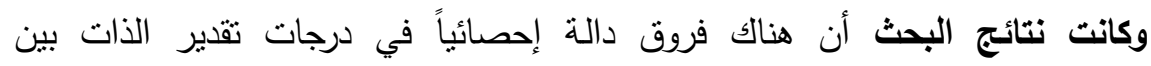

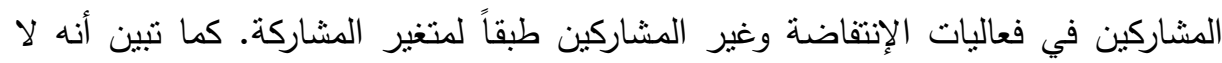

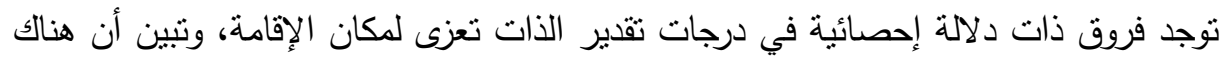

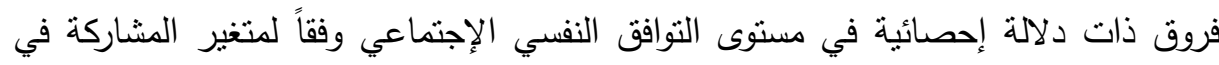

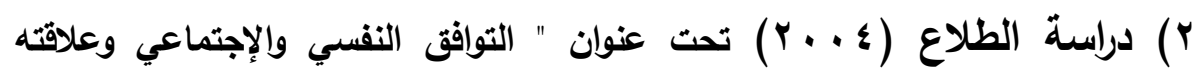
بالإنتماء لاى الأسرى المحررين من السجون الإسرائيلية" وذلك في ضوء متغيرات مكان

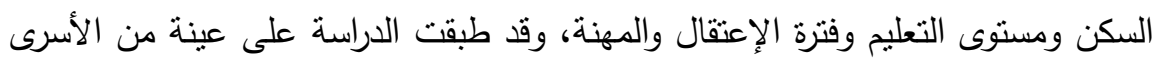

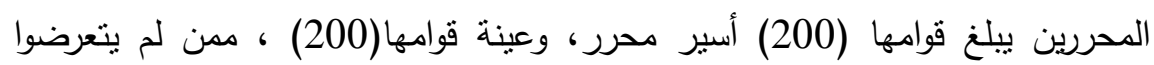

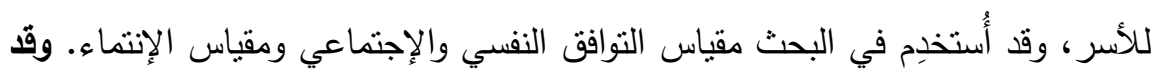
توصلت الاراسة إلى عدم وجود فروق في التوافق النفسي والإجتماعي بين الأسرى وبين

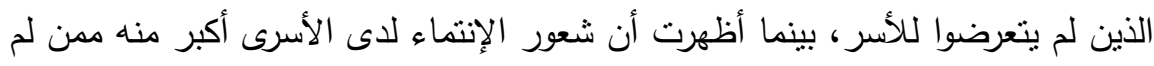

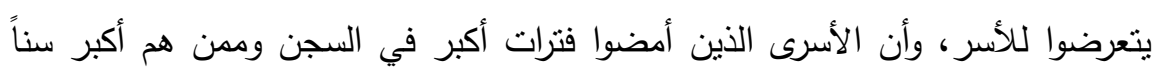
وذوي مستوى تعليمي أعلى، أكبر قدرة على التكيف النفسي والإجتماعي ممن لم ينعرضوا للأسر ولم يكونوا في مستوى الأسرى التعليمي والسن. 
ب) دراسة بيلتري (2002) (Pellitteri) تحت عنوان -Self Concept and Self) Esteem in Elementary Children. Psychology in the Schools . "31,164-171. وهدفت الدراسة إلى التعرف على العلاقة بين الإتزان الإنفعالي وآليات

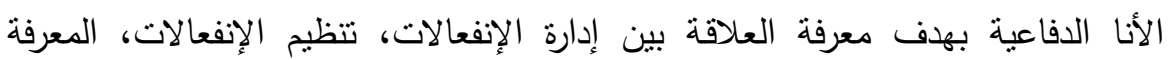
الإنفعالية، وعوامل الثخصية الني لها علاقة بالتكيف. وقد تكونت عينة البحث من

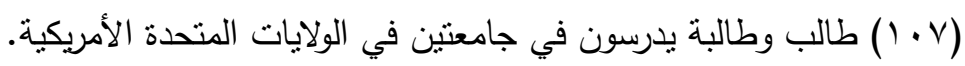

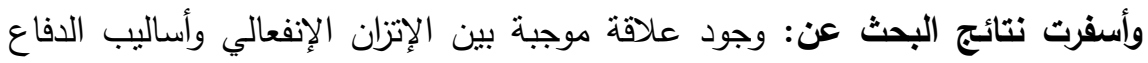

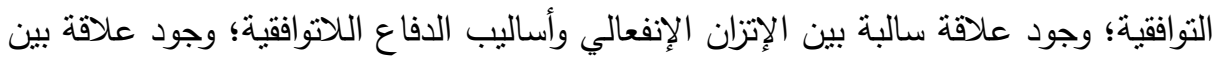
أساليب الدفاع التوافقية والمعرفة الإنفعالية؛ عدم وجود علاقة بين أساليب الدفاع التوافقية وكلٍ من إدارة الإنفعالات وتتظيم الإنفعالات؛ وعدم وجود فروق في العلاقة بين الإتزان الإنفعالي

$$
\text { والعوامل الثخصية تعزى لمتغيرات (الجنس، المستوى الدراسي). }
$$

צ) دراسة Koubekova (2000) : تحت عنوان "مستوى التوافق الشخصي والإجتماعي لادي المعاقين حركياً". وهدفت الدراسة الى معرفة مستوى التوافق الثخصي والإجتماعي

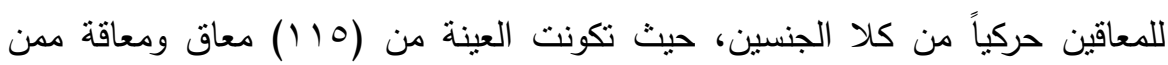

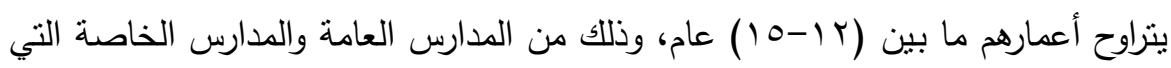
تعلم المعاقين حركياً، وقد أُستخدت للاراسة أدوات شارف شملت على إختبار كاليفورنيا للشخصية وإسنبيان القلق كحالة والقلق كسمة وإستبيان تقدير الذات.

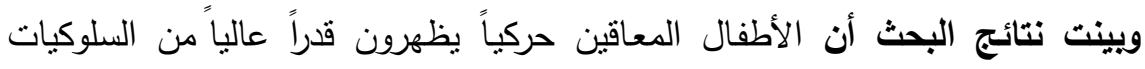

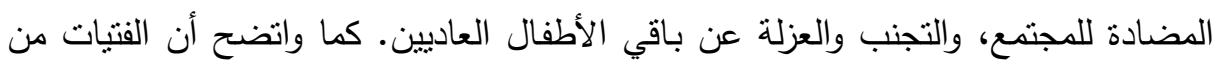
المعاقات كن يواجهن صعوبات في التوافق الإجتماعي أكثر من أقرانهم من الذكور المعاقين.

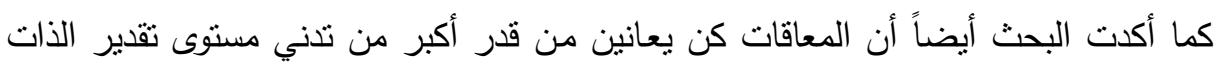

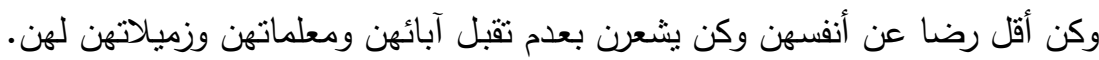




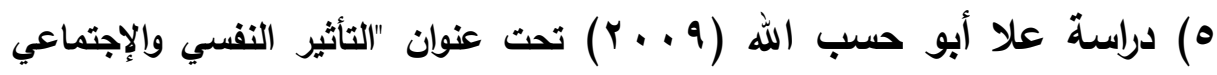

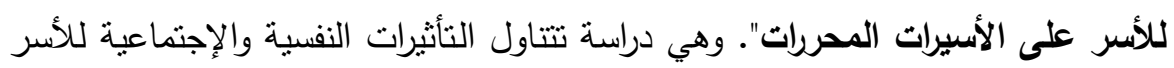

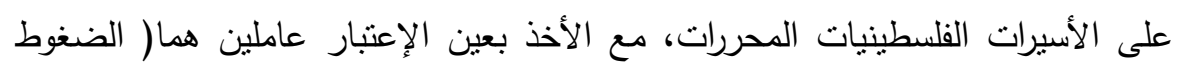

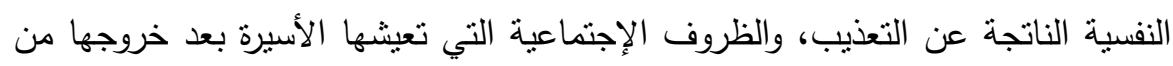

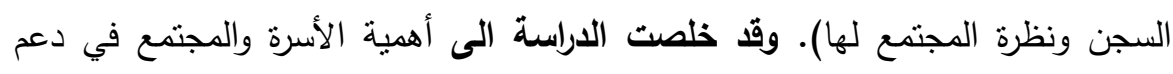

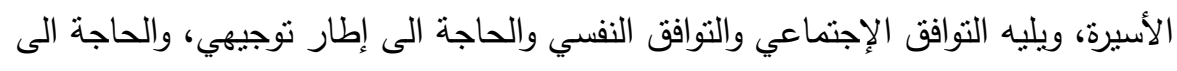

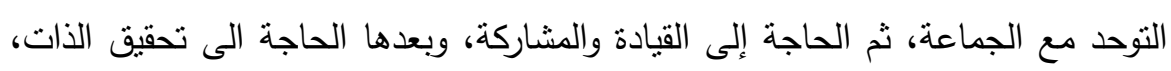

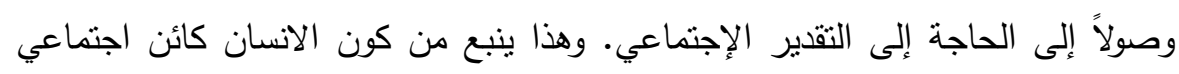
بطبعه ولا يمكنه أن يعيش بمنأى عن الجماعه.

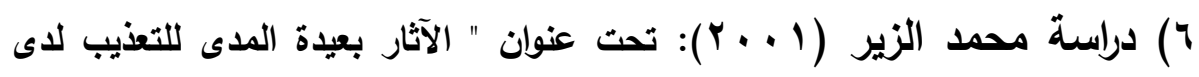

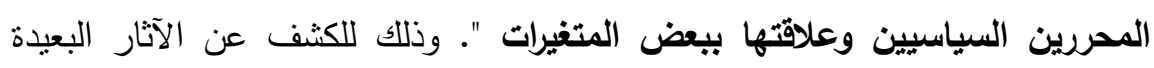

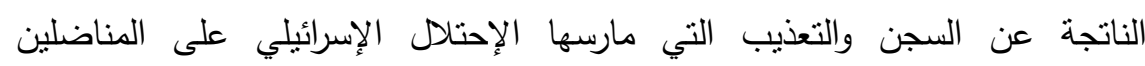

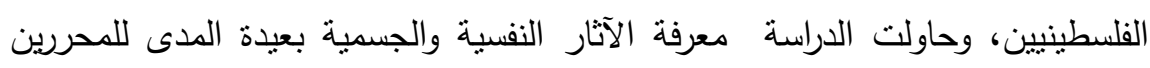

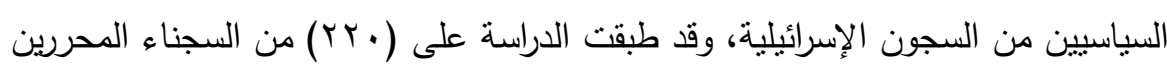

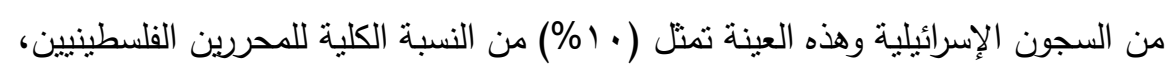

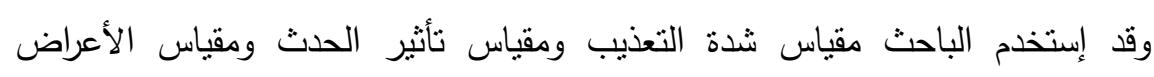

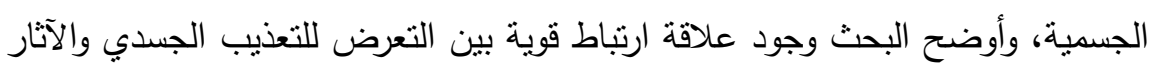

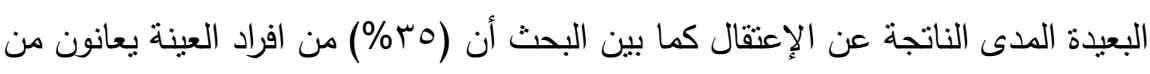

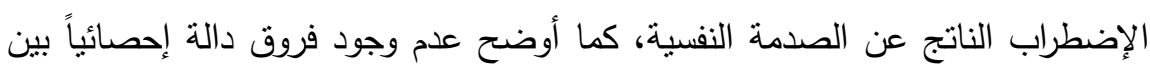
مستوى كرب ما بعد الصدمة والأمراض النفسية بعيدة المدى تعزى لعمر السجين عند العند

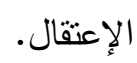




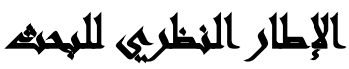

مفهوم ميكانيزمات/ آليات التوافق الأتي: ويتضمن سيكولوجية التوافق: الإنسان يعيش في بيئة منتوعة من العلاقات، وهذا ينعكس على سلوكياته ودوافعه المختلفة مما يتطلب

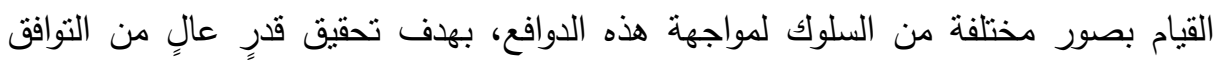
النفسي والإجتماعي، فالإنسان عندما يشعر بخطر يهدد حياته يبحث عن مكان آمن يلجأ إليه،

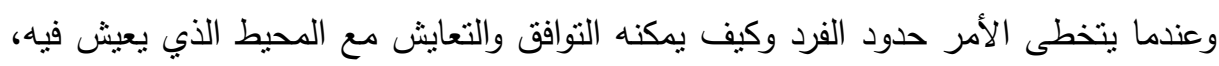
هنا يلجأ الفرد إلى التعايش مع البيئة والمحيطين، وليس معنى التوافق الثخصي والإجتماعي

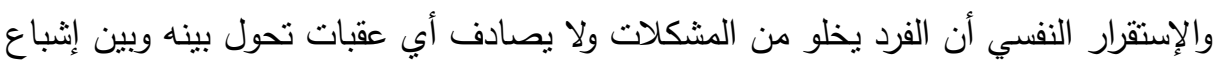

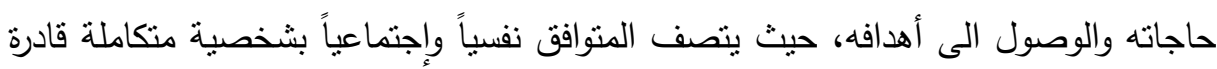
على التتسيق بين حاجاته وسلوكه الهادف وتفاعله مع بيئته، الذي يتحمل عناء الحاضر من

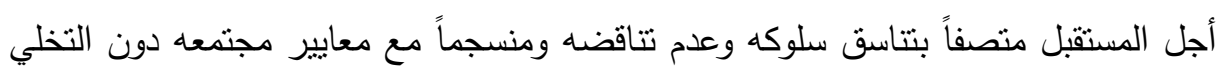

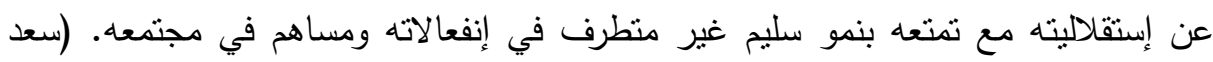

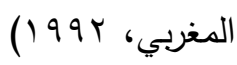
مفهوم الأسر والأسير في القانون الدولي: يشير مصطلح " أسبر حرب " كما هو

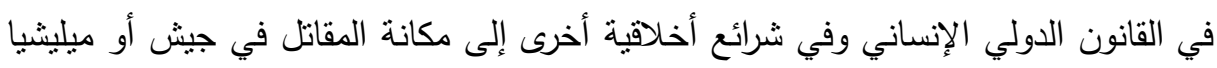

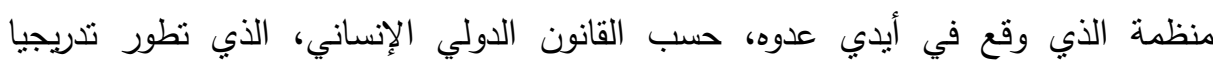

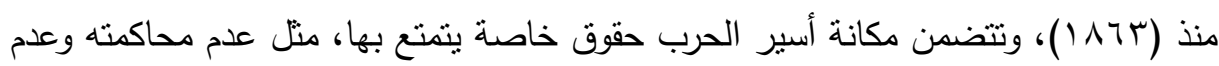
تعرضه للتعذيب، تلقي علاج طبي كامل، الإستعانة بمنظمة الصليب الأحمر الدولية لمراقبة

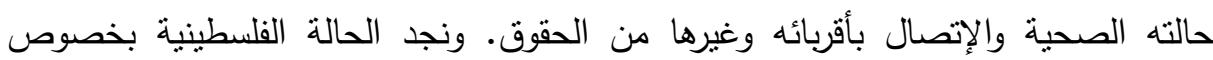

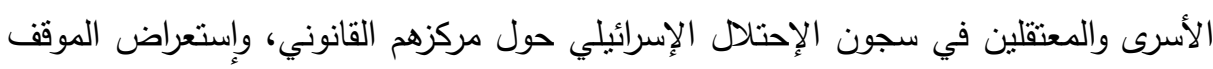

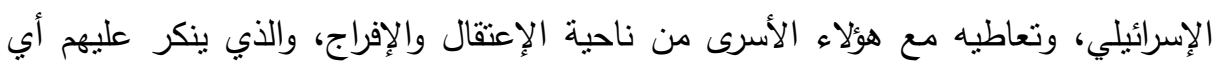

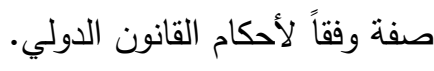


أثكال وعواقب التعذيب الممارس بحق الأسرى الفلسطينيين: يعاني الأسرى

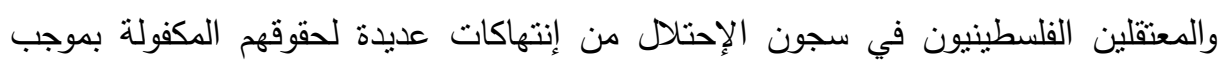
الأعراف والإتفاقيات الدولية الدكونة للقانون الدولي الإنساني والقانون الدولي لحقوق الإنسان.

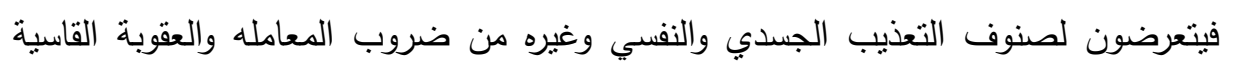

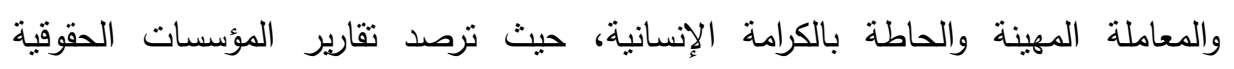

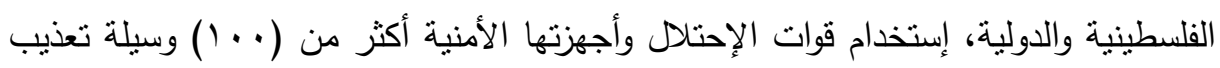

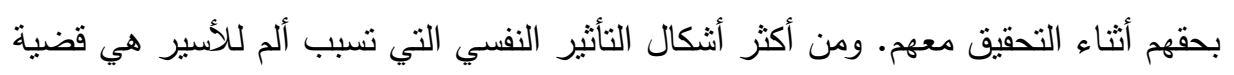

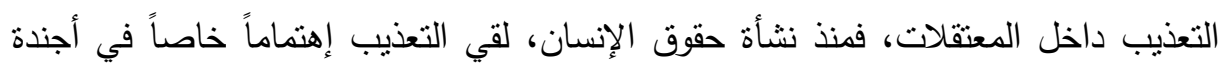

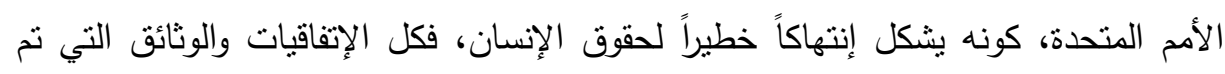

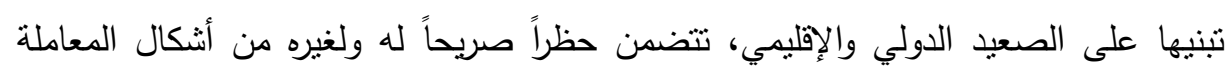

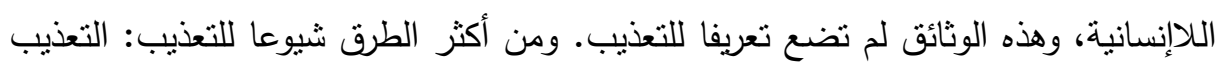

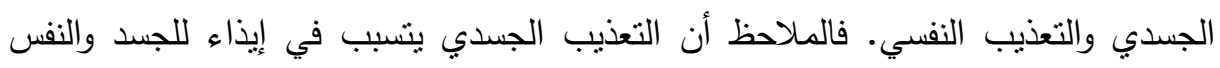

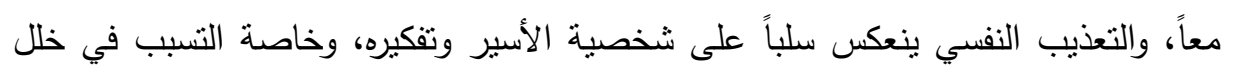

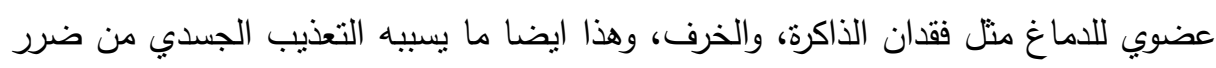
لللاماغ في حالة الضرب على الرأس. النظريات المفسرة لمفهوم التوافق: يعتبر البعد النظري لنفسير أية ظاهرة الأساس في النسان

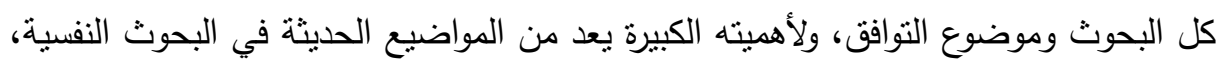

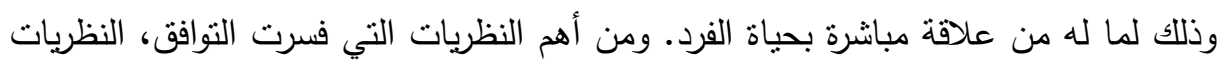

النظرية البيولوجية الطبية: Biological medical theory: ويقرر مؤيدوها أن جميع

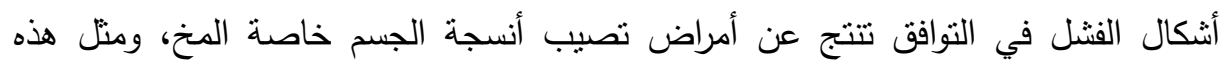

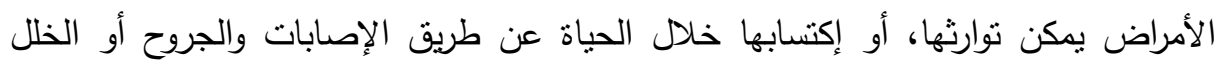

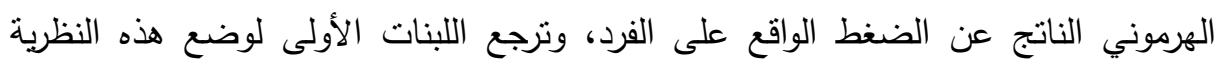
لجهود كل من داروين، مندل، جالتون، كالمان، وغيرهم. (مدحت عبد الحميد، . 99 (19) ) 


\section{النظرية النفسية: Psychological Theory} نظريات التحليل النفسي - Psycho-analysis Theories يرى أصحابها أن الحياة عبارة عن سلسلة صراعات تعقبها إثباعات أو إحباطات، كما تفترض هذه المدرسة ان الثخصية

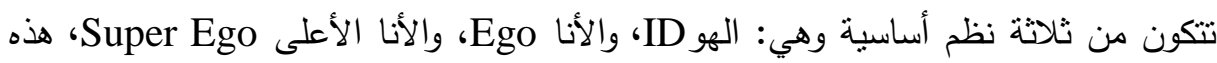
جميعاً تتفاعل معاً تفاعلاً وثيقاً بحيث يصعب وهي: فصل نتأثير كل منهما، وأن السلوك في الغالب

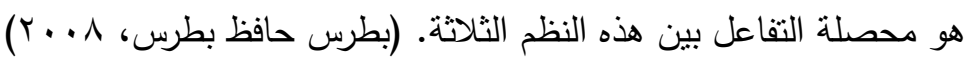
كما أن الثخص حسن التوافق في نظر فرويد هو الذي تكون عنده "الأنا" بمثابة المدير

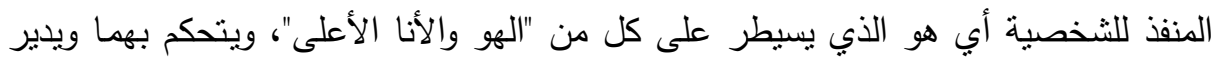

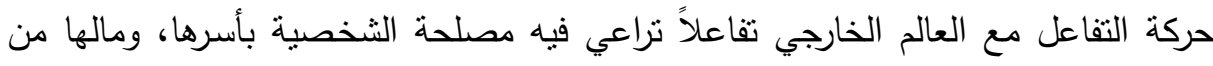
حاجات، هذا من ناحية، ومن ناحية أخرى فإن التوافق الحسن عند الفرد يكون بإدراكه الشعوري لدوافعه وتكيفها لمطالب الواقع. ويرجع فرويد سوء التوافق إلى مرحلة الطفولة بخبراتها

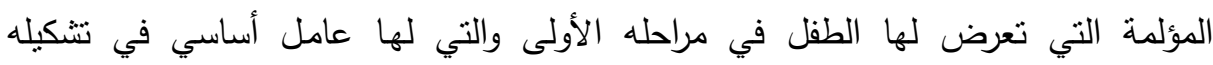

$$
\text { الثخصي. (أميرة عبد العزيز الديب، . • (199) }
$$

والثخصية من وجهة نظر فرويد هي أسلوب الفرد الذي يستخدمه من أجل تحقيق التوافق، هذا الأسلوب يتميز بتأثره بالعوامل السيكولوجية والفسيولوجية، وتتمنل في الغرائز واللبيدو، وتتحصر الغرائز عند فرويد في غريزة الحياة وغريزة الموت، وتتمنل في العدوان.

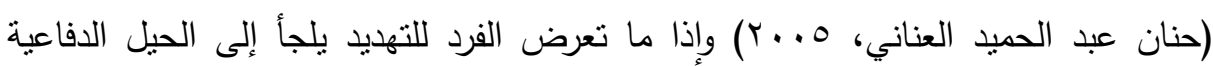

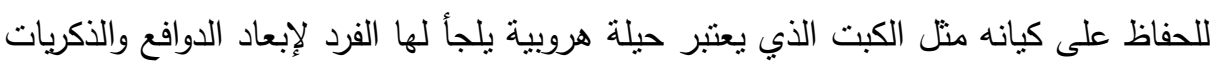

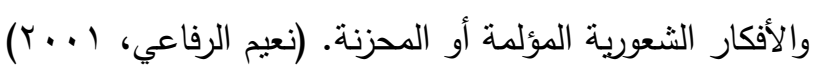

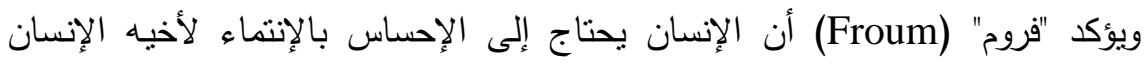

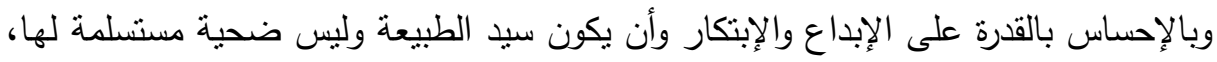
وأن يشعر بالإستقلال الذاتي. ويحتاج إلى فلسفة وعقيدة في الحياة، ويدل رأي فروم على ألى أله

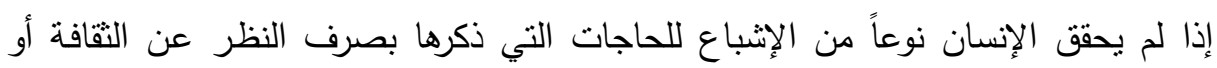


المجتمع الذي يعيش فيه فإنه سيعاني من إضطرابات إنفعالية. (مرسي سيد عبد الحميد،

يتضح مما سبق أن سوء التوافق كما ذكره فرويد يرجع إلى الخبرات المؤلمة في السنوات

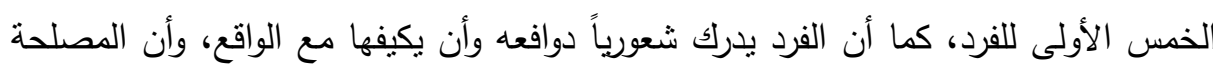
العليا للفرد هي التي تدير الأنا في حركة التفاعل مع العالم الخارجي.

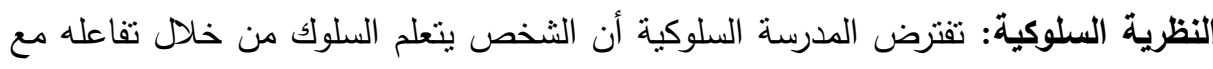
البيئة، وعلى هذا الأساس يجب وصف الأشخاص بكائنات إستجابية، ويستجيبون للمثيرات

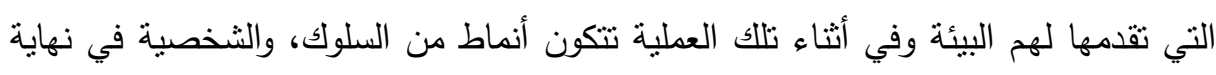
الأمر • (يوسف مصطفى القاضي وآخرون، (9191) ويرى رواد هذه المدرسة أن عملية التوافق أنق تكمن في إكتساب الفرد لمجموعة من العادات المناسبة والتي تتميز بالفعالية إتجاه الآخرين،

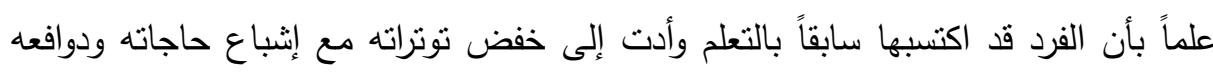
وهذا أكسب الفرد سلوكاً يستدعيه وقت ألحاجة وبالتالي يؤدي هذا السلوك المتكرر إلى خفض إنى التوتر الناتج عن إلحاح الدوافع ويكون ثناته حسب عدد مرات التدعيم وقدرة الإثابة التي وفرها.

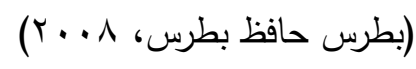
كما يؤكد السلوكيين على أن السلوك بصفة عامة ناتج عن مثير وإستجابة وأن عدم

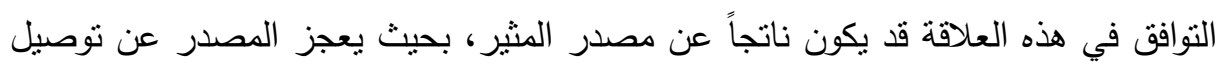
ما يريده الإنسان بالثكل الصحيح وقد ينتج عن الشخص الذي يقوم بالإستجابة وهذا إما لفال

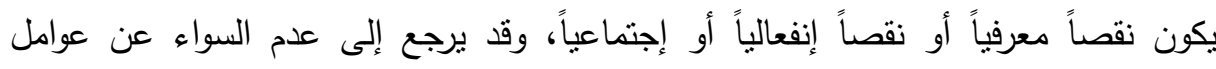

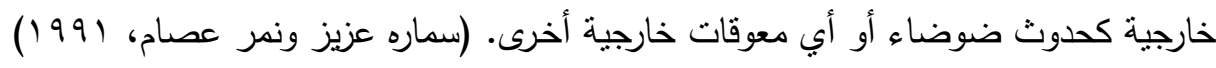

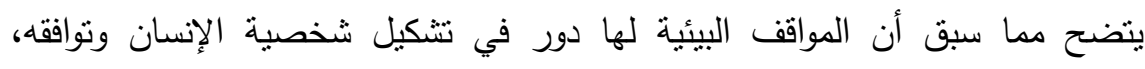
والتوافق عند السلوكيون ينأنى عن طريق البيئة الإجتماعية والبيولوجية المحيطة، بحيث لئن أننا نكتسبه عن طريق هذه المثيرات والمنبهات التي تعطي إستجابات مناسبة. النظرية الإنساتية: يركز رواد هذا الإتجاه على خصوصية الإنسان بين الكائنات الحية، فيرى كارل روجرز (Rogers) أن التوافق والإنسجام يتحقق للفرد عندما تكون الذات المثالية للفرد Relf-Ideal-Self والذات الحقيقية Real على استقامة واحدة، فيرى روجرز أن أن 
الثخص الفعال هو الذي يعمل إلى أقصى مستوى، ويتسم بالإنفتاح على الخبرات ويكون

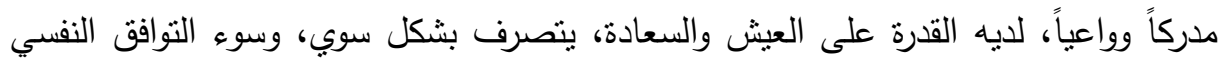

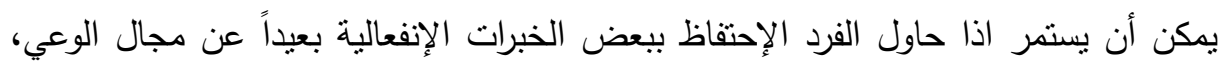

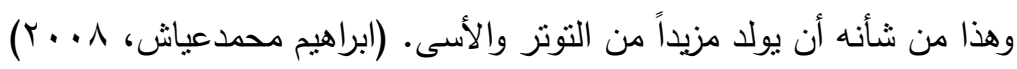

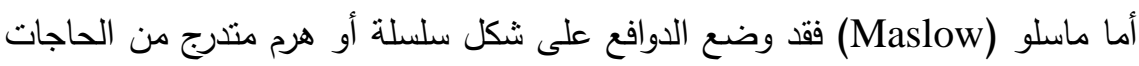

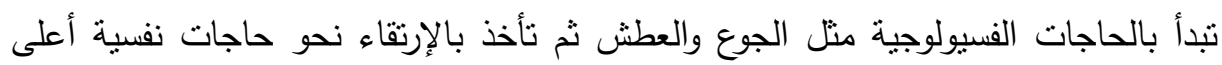
كالحاجة الى الأمن والإنتماء والحب والتقدير الإيجابي وتحقيق الذات وأن التوافق برتبط بتحقيق الذات، وأن سلوك الإنسان في الحياة لبس محكوماً بالدوافع على الإطلاق، بل محكوماً

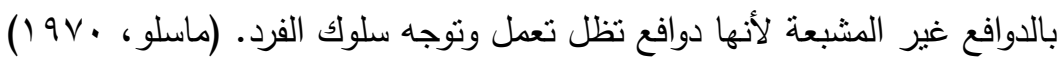
يتضح مما سبق أن المدرسة الإنسانية تتظر إلى سلوك الإنسان كإنسان، وأنه مزود

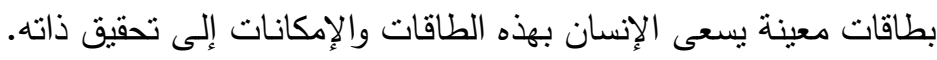

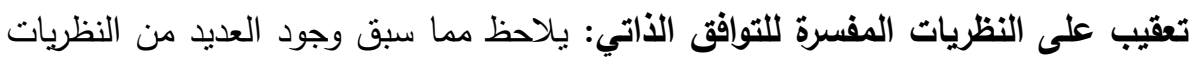

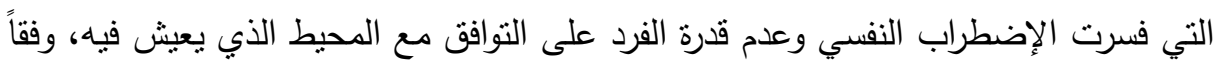

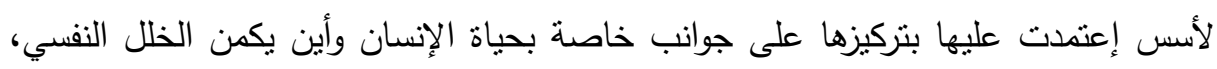

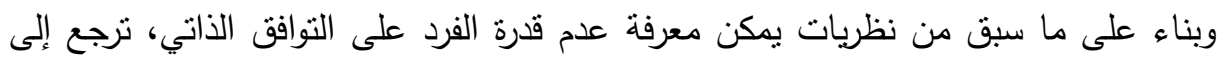
مجموعة من عوامل، أهمها: ( ) خلل جسمي مرتبط بالهرمونات وكيمياء الجسم والغدد والأدرينالين...الخ.

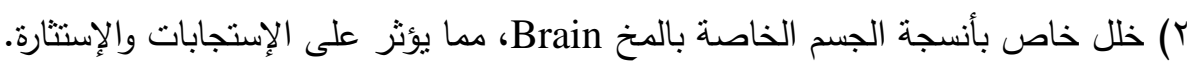
r) عدم إثباع الدوافع، واللجوء إلى الأساليب الدفاعية. ع) الأفكار السلبية التي تولدت اتجاه نفسه واتجاه الآخرين، وشعوره بعدم القدرة على السيطرة الألى على المواقف والأحداث. 0) اليأس، وانخفاض الثُعور بالكينونة. 


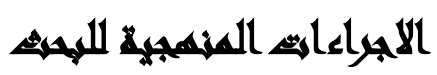

منهج البحث: عالج الباحثون البيانات وفق نهج الإحصاء الوصفي: منوسطات حسابية،

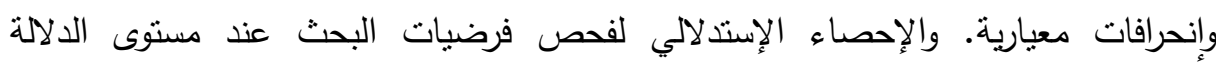

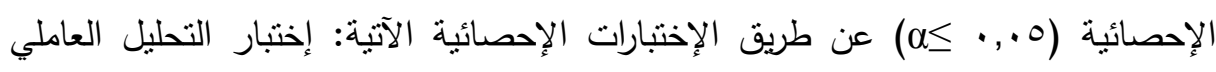

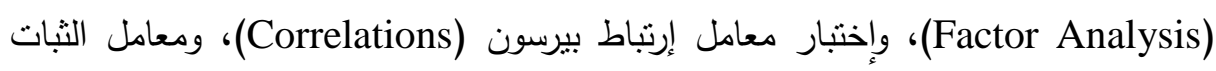
كرونباخ ألفا (Cronbach alpha) وذللك بإستخدام برنامج الرزم الإحصائية للعلوم الإجتماعية (SPSS).

$$
\text { إجراءات البحث: وتضمنت الإجراءات الآتية: }
$$

• مراجعة الأدب التربوي والدراسات السابقة ذات الصلة الإداءت بالبحث الحالي.

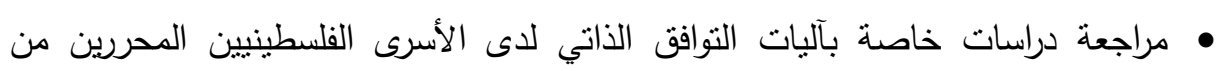
السجون الإسرائيلية. • تحكيم أدوات البحث من قبل محكمين مختصين والأخذ بتعديلاتهم. • تطبيق أداة البحث على مجتمع البحث. • • • رصد النتائج في جداول خاصة وتحليلها.

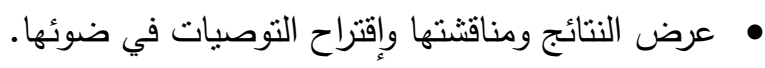

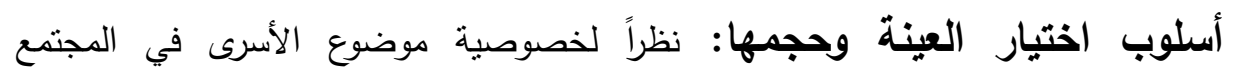
الفلسطيني، فقد نم إختيار العينة بأسلوب العينة ألعددية بالتتسيق مع المؤسسات والتتظيمات

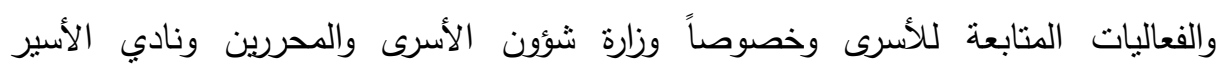

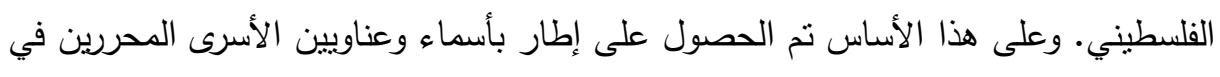

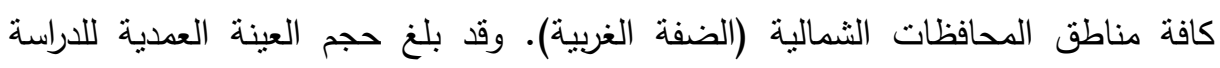
الميدانية (100) أسير ما بين ذكر وأنتى، ممن قضوا مدد مختلفة داخل السجن، كما تم

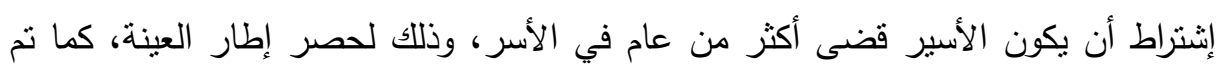
إختيار الأسرى الذين تم تحريرهم خلال الخمس سنوات الأخيرة السابقة للبحث. 
نوعية البيانات التي تم جمعها: لدراسة آليات الثوافق الذاتي للأسرى الفلسطينيين

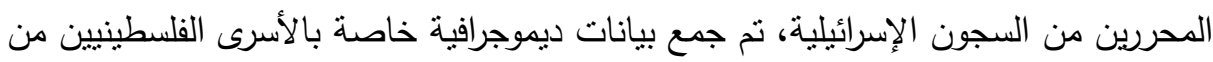

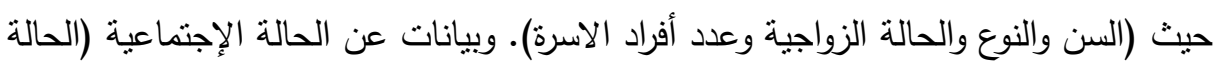

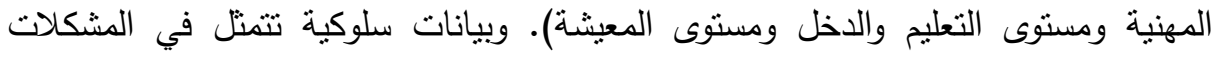

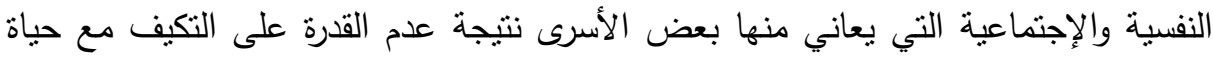

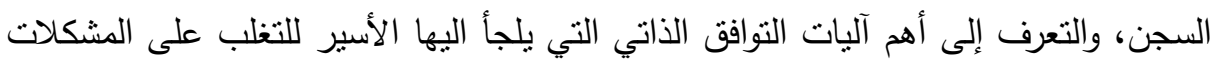
النفسية والاجتماعية الني يواجهها. حجم العينة: تم جمع البيانات من عينة عددية من الأسرى الذين نحرروا من السجون

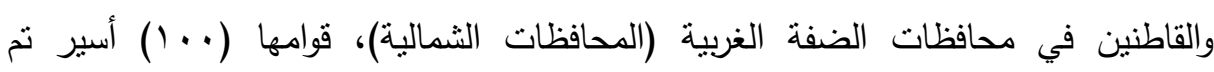
تقسيمهم على المحافظات.

إطار العينة ومجتمع البحث يتكون مجتمع البحث من الأسرى الفلسطينيين المحررين من

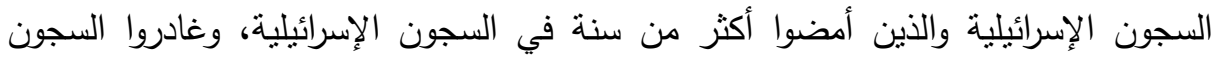

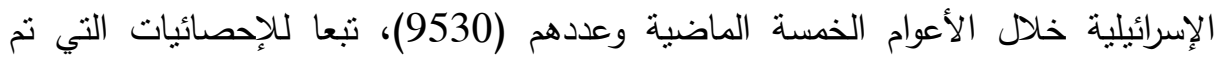
الحصول عليها من هيئة شؤون الأسرى والمحررين.

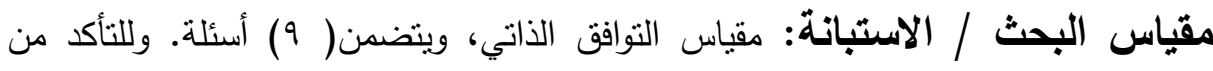

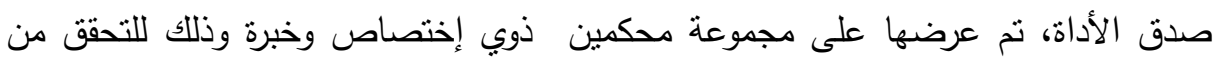
صدقها، والطلب منهم إبداء آرائهم حول فقرات الأداة التي تم تصميمها من قبل فرئ فريق البحت

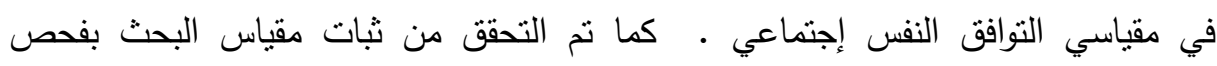

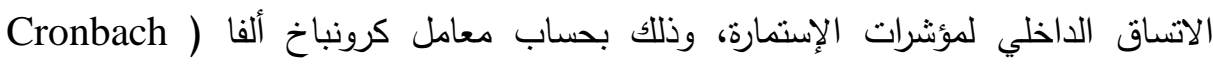
(alpha (âv) 
مفهوم ونتائج التحليل العاملي: إن التحليل العاملي عملية رياضية نهتم بتصنيف

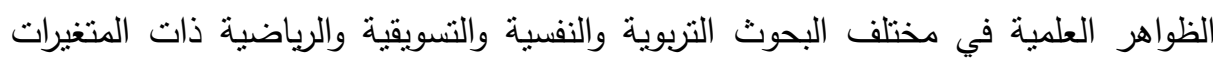
المتعددة، وهو أسلوب إحصائي يستهدف تفسير معاملات الإرتباط التي لها دلالة إحصائية بين مختلف المتغيرات، أي تبسيط الإرتباطات بين مختلف المتغيرات الداخلة في التحليل وصولاً إلى العوامل المشتركة التي تصف العلاقة بين المتغيرات وتفسيرها، حيث يهذف الإنيات التحليل العاملي إلى تقليل حجم البيانات وتلخيصها والإقلال من المتغيرات العدية إلى إلى عدات

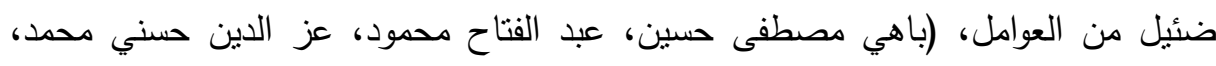

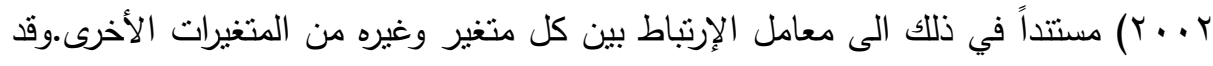

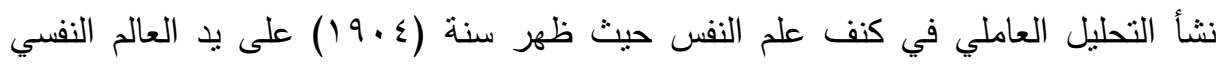
الإنجليزي شارل سبيرمان صاحب معامل الإرتباط الرتبي بهدف قياس الذاء الفاء. تحليل البيانات: تحليل العوامل لإستمارة مقياس التوافق الذاتي: يحتوى محور التوافق الذاتي على (9) متغيرات وهي: متغيرات محور (التوافق الذاتي):

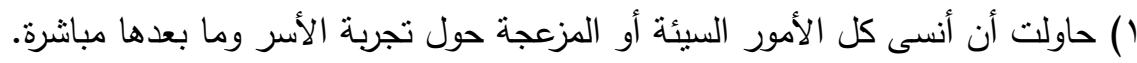

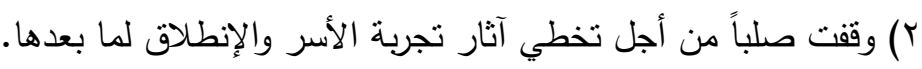

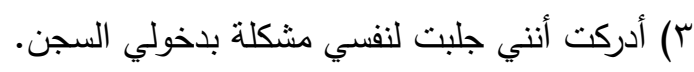
ع ع اولت الإحتفاظ بمشاعري لنفسي.

() بدأت انشعر بأن تجربة الأسر وما بعدها جعلتني أقوى مما كتت عليه في السابق.

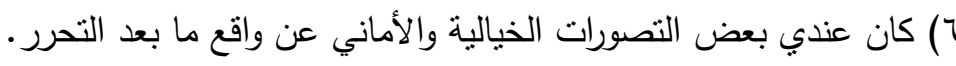

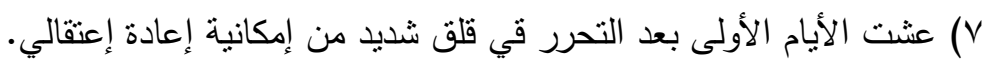

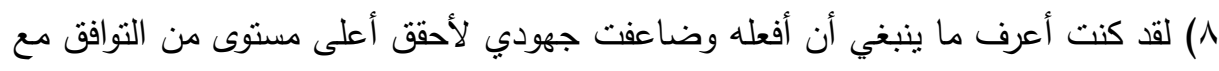
نفسي وأسرتي ومحيطي. 9) حاولت ضبط شعوري بالإحباط والقهر قدر الإمكان وعدم عكسها في سلوكي بعد خروجي

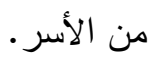


حيث أن المحاولة الأولى لتحليل العوامل لهذه المتغيرات قد بينت النتائج التالية: 1. على مستوى جدول الإرتباطات الأولية Correlation Matrix فإنه يوجد عدد من لإن

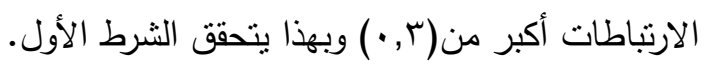

Kaiser-Meyer-Olkin Measure of Sampling على مستوى كفاءة التعيين الكلية فإن قيمة الإختبار هو (YTequacy يتحقق الثرط الثاني. r. على مستوى كفاءة التعيين الجزئية (MSA)، فإنه وبالنظر إلى الإرتباطات الجزئية في

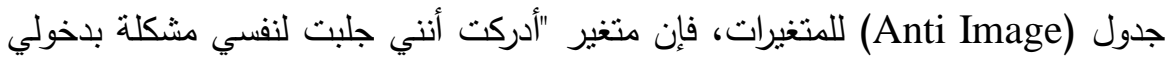

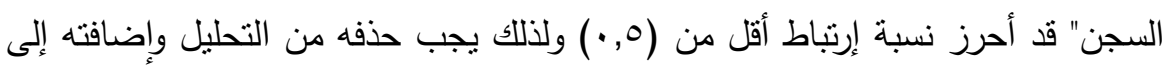
قائمة المتغيرات الأساسية وإعادة التحليل إلى العوامل بدونه في المحاولة إنهاط الثانية. ع. يتضح في المحاولة الثانية أن جميع المتغيرات ذات إرتباطات جزئية اكبر من (ه, •).

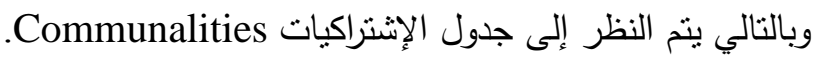
๑. ويتضح من جدول تحليل الإشتراكيات Communalities في المرحلة الثانية أن سؤال "بدأت اشعر بأن تجربة الأسر وما بعدها جعلنتي أقوى مدا كنت عليه في السابق" ومتغير" حاولت الإحتفاظ بمشاعري لنفسي". هما الأقل قيمة ولذلك يتم حذفهم وإدراجهم في قائمة التها المتغيرات الأساسية للمحور وإعادة التحليل للمحاولة الثالثة. T. وبالإطلاع على تشبعات العوامل بطريقة تدوير العوامل VIRAMAX يتضح من خلال

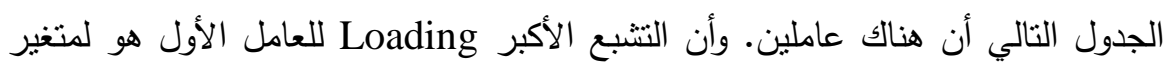

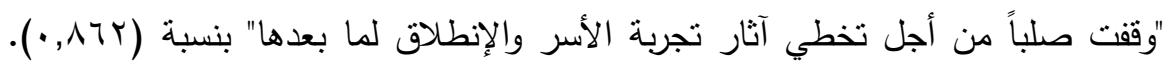

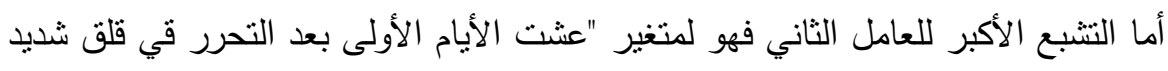

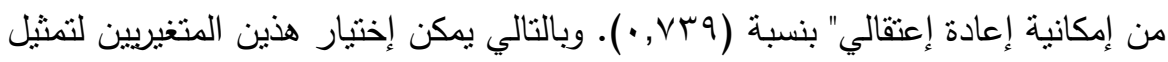

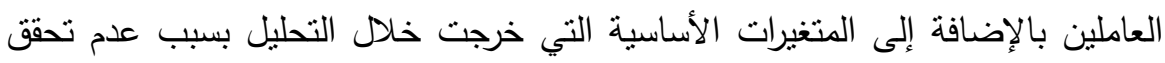

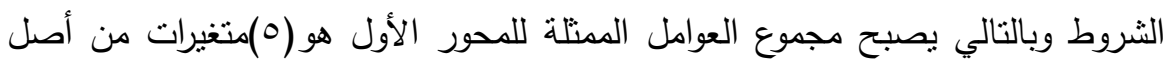

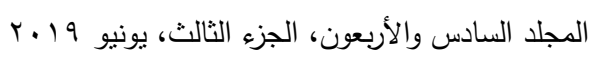




\section{المندائم}

بالنظر إلى النتائج المدرجة ومقاربتها مع العلاقات الدالة إحصائياً في تحليل التباين الأحادي يتضح مدى إنساق البيانات على المستويين التحليلين، أبي التباين الأحادي والتحليل

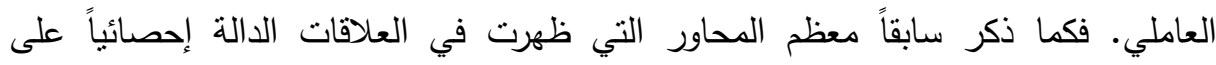
المستوى التحليلي الأول (التباين الأحادي) عادت وظهرت نفسها على المستوى التحليلي الثاني

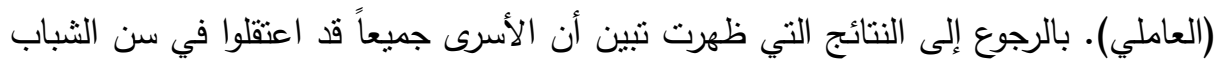

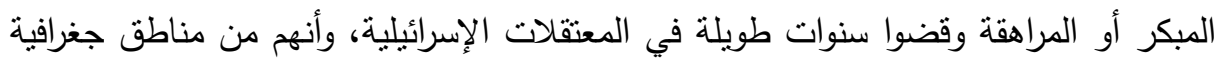

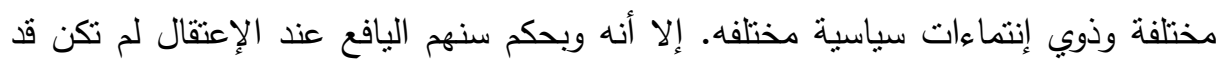

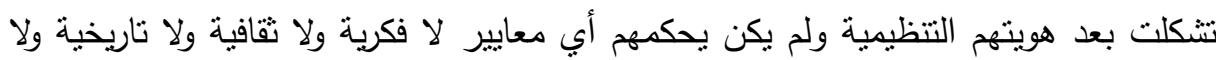
دينية. ببساطة كان إيمانهم نابع بضرورة مقاومة الإحتلال الذي يقتحم قراهم ومدنهم ويهدم

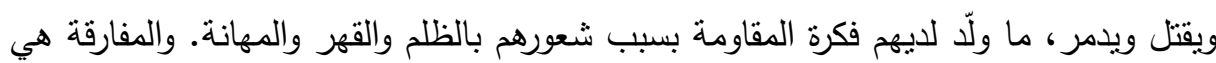

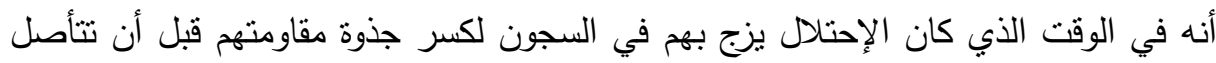

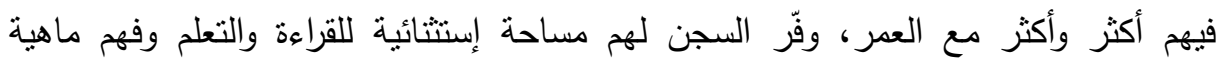

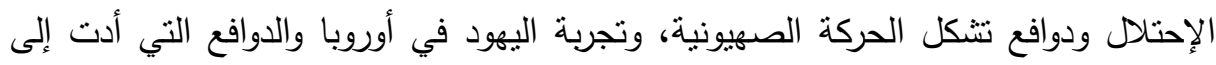
تخلص أوروبا من اليهود وتصديرهم إلى فلسطين. وهذا أدى الى إكتثاف جوهر وحقيقة ودوافع الئح

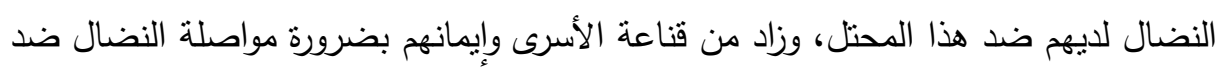

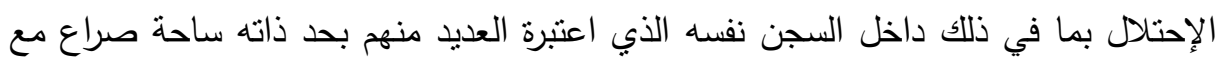
الإحتلال، وهكذا فقد تغيرت الأمور لدى الأسرى بحكم تغير فهمه للحياة، وتطورهم إنسانياً

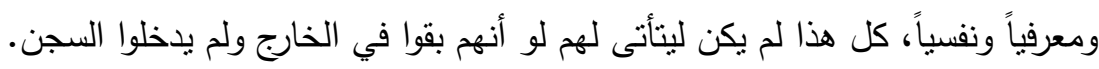
نال محور النوافق الذاتي ومضامينه نصيباً وافراً في مفردات ومساحات التعبير وأثنكالة

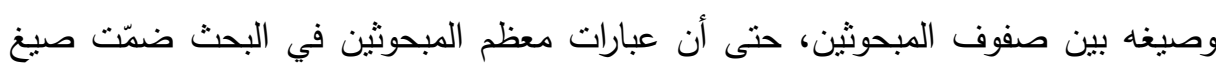
تحمل معنى بلغ حد التطابق أحياناً لمعظم مؤشرات المحور في المقياس المستخدم في البحث.

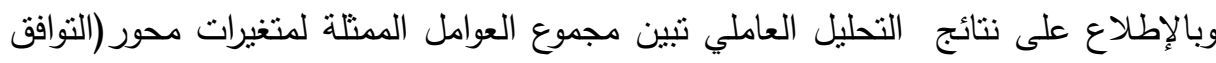
الذاني) في استمارة مقياس التوافق النفسي والإجتماعي هي: 


\begin{tabular}{|c|c|c|}
\hline عامل 1" & وققت صلبا من أجل تخطى آثار تجربة الأسر والإنطلاق لما بعدها & 1 \\
\hline اساسى & أدركت أننى جلبت لنفسى مشكلة بدخولى السجن & r \\
\hline اساسي & حاولت الإحتفاظ بمشاعري لنفسي & r \\
\hline اساسي & بدأت اشعر بأن تجربة الأسر وما بعدها جعلنتى أقوى مما كنت عليه فى السابق & $\varepsilon$ \\
\hline 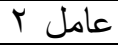 & قي قلق شديد من إمكانية إعادة إعتقال & 0 \\
\hline
\end{tabular}

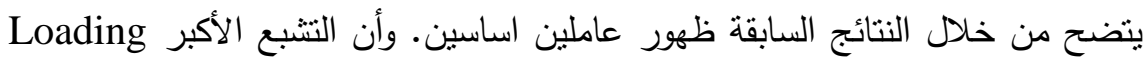

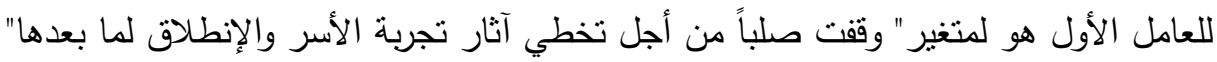

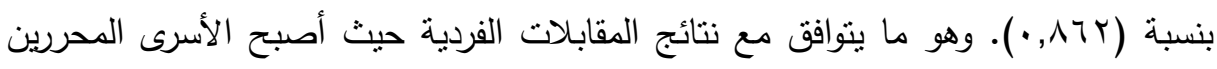

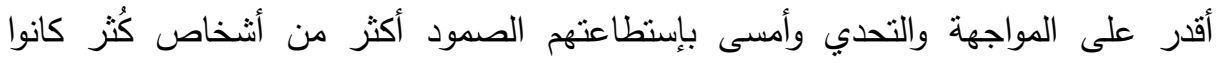

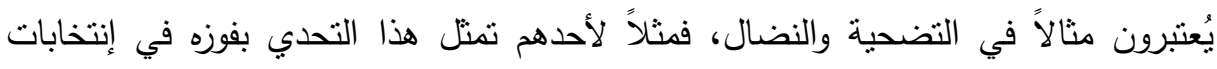

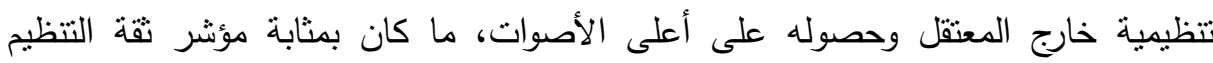
بقدرات الأسرى المحررين على القيادة، وشكل دافعاً قوياً لذلك الأسير للإستمرار في النشاطات النابه

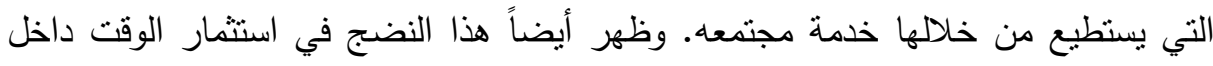
السجن بما هو مثمر ومفيد للأسير لتفويت الفرصة على السجان لقتل روح الأسير وإيمانه بذاته وقضيته وجعله يندم على ما بذل من أجلها. وانسحب هذا النضج أيضاً خارج السجن النئ وساعدهم على فهم أعمق للحباة وأن تجربة الإعتقال تحولت من تجربة لبن موت كما يصبو إليه

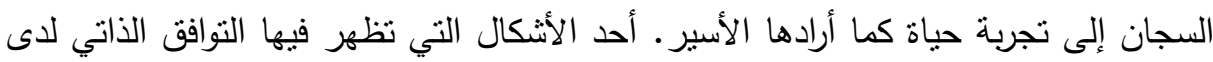
الأسرى داخل السجن وإنسحب على خارجه هو أنه ساعدهم على فهم أعمق للحياة، كما يقول أحدهم؛" ..أدى الى تغيير في نظرتي للحياة، حيث لم أكن مقدر لمعنى الموت، وهنا أصبحت

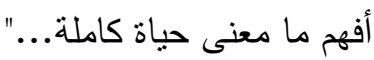

هذا وقد أجمع كافة الأسرى الذين تمت مقابلتهم وبنسبة وصلت إلى ( ..1\%) على أن لمسألة التوعية والتثقف داخل السجن الدور الرئيس في مسألة الإندماج وصياغة شخصية الأسير وفكره على المدى القريب والبعيد. فقد كان للدورات والجلسات التتظيمية التي كانت تعقد داخل السجون وبشكل منتظم الأثر الأكبر في صقل شخصية ولهية الأسير وإكتساب التقة

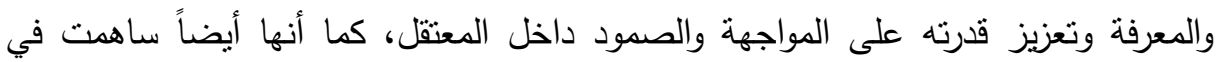
تمكينه نفسياً وإجنماعياً في تسريع عملية إندماجه مع باقي الأسرى وتوافقة إجتماعياً وإنسانياً

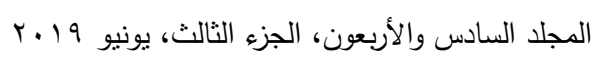


داخل بيئة السجن على قسوتها وبشاعتها. وفي وصفه لهذا الجانب من تجربة الإعتقال

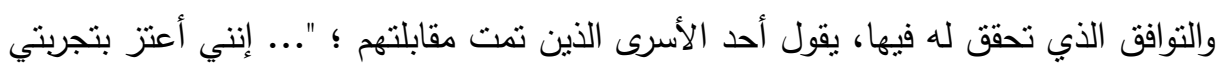

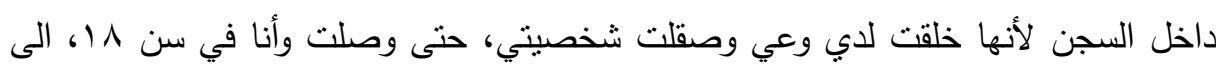
موجه عام داخل السجون. وبدأنا ممارسة حقنا في المطالبة بحقوق الأسرى داخل المعتقلات

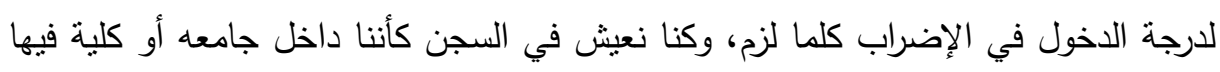

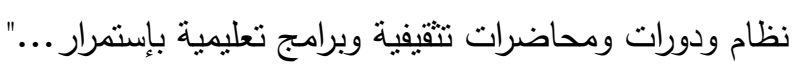

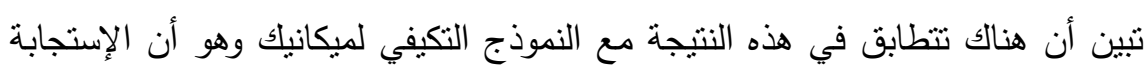

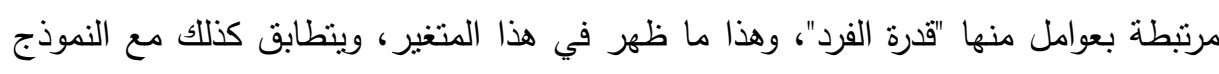

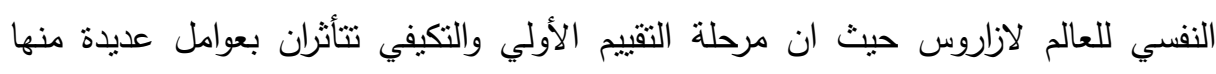

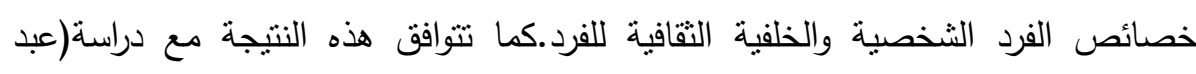

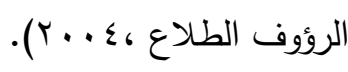

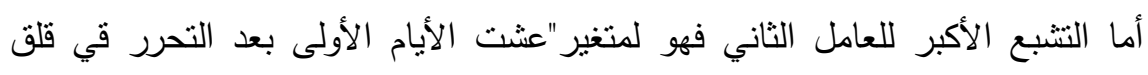

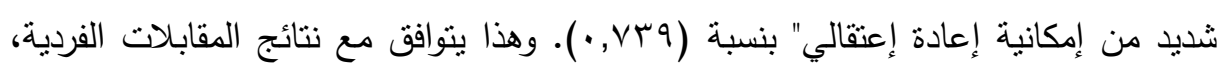

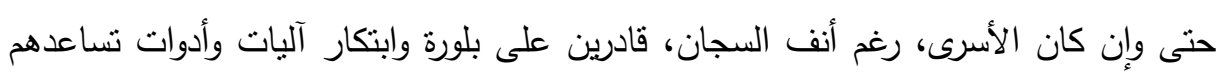

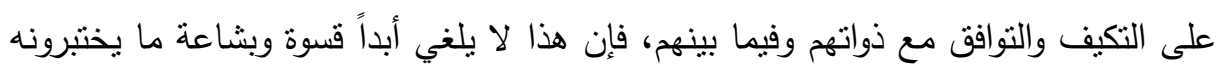

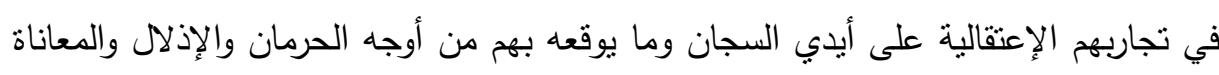

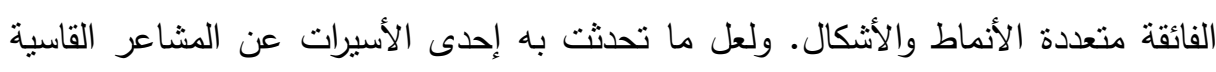

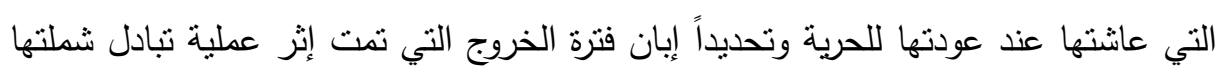
وأسرى آخرين بعد أن أمضت ما يزيد عن (• () سنوات في المعتقل، حيث نقول؛ ".... كان

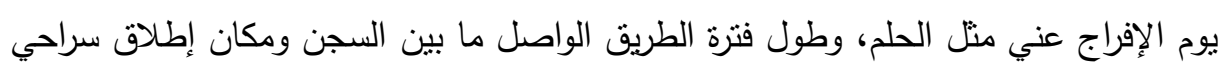

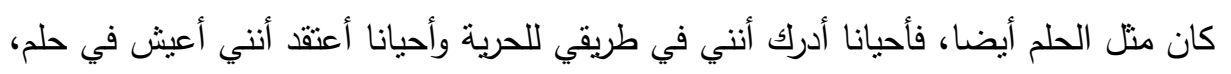

$$
\text { وفي رعب كبير من أن تلغى الصفقة..." }
$$

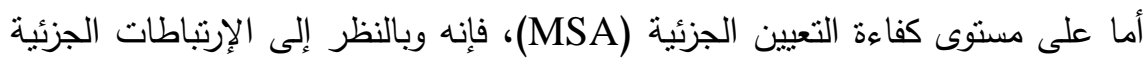

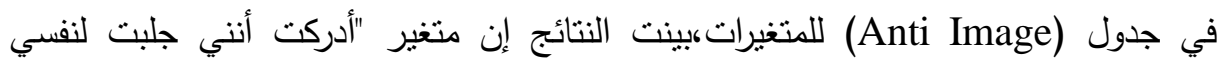

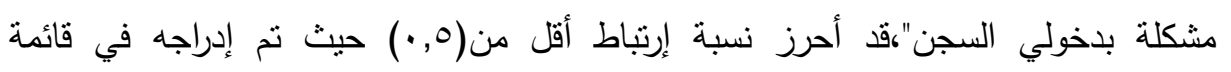


المتغيرات الأساسية لمحور التوافق الذاني. حيث نتوافق هذه النتيجة مع نظرية الإنعصاب

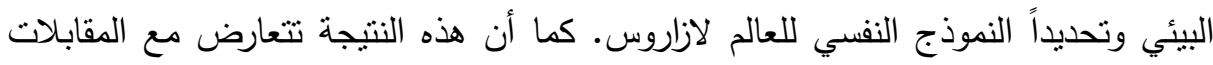

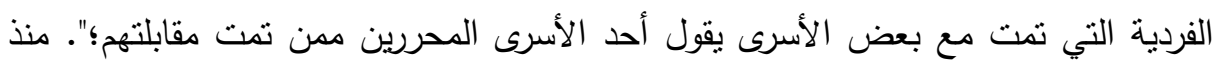

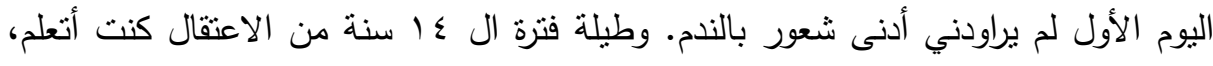

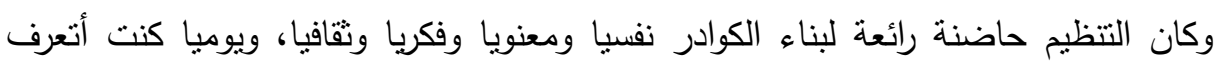

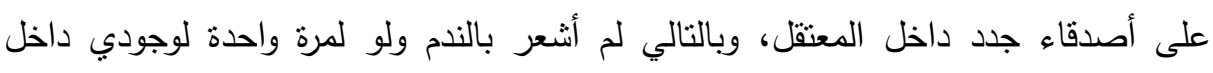

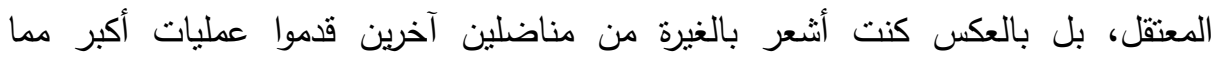

كما بينت بعض نتائج المقابلات الفردية تعارض مع هذه النتيجة وتعبيراً عن إعتزازها

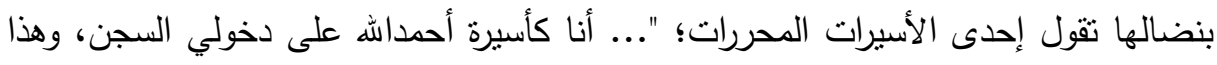
ليس نابعاً من حالة إحباط، أو أن حياتي كانت جحيم خارج السجن، بالعكس كانت حياتي جميلة، ولكن الأسر صقل شخصيتي وجعل لي كيان أعتز به وأفخر، وهو كياني كمناضلة

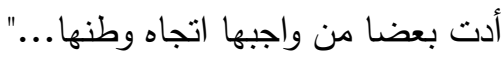
كما بينت نتائج تحليل الإثتراكيات Communalities أن سؤال " بدأت اشعر بأن أشان

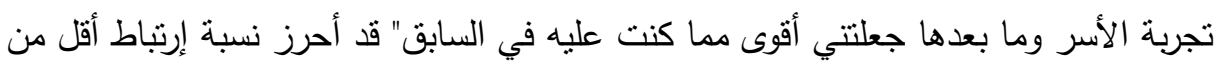

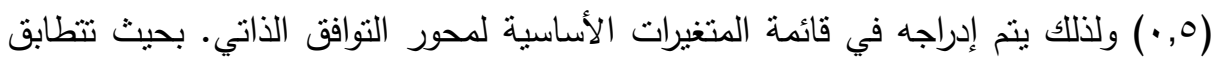

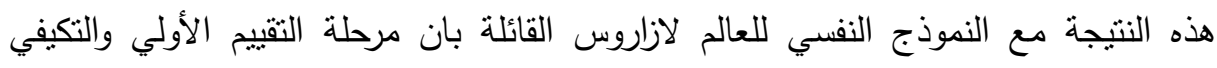
تتأثران بعوامل عديدة منها خصائص الفرد الثخصية والخلفية الثقافية للفرد. كما تتوافق هذه لأنه النتيجة مع نتائج المقابلات الفردية. وقد أكد معظم الأسرى في مقابلاتهم أن قرار الحكم مهما كانت مدته يمثل حالة إستقرار بالنسبة للأسير .

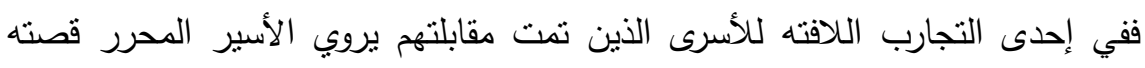

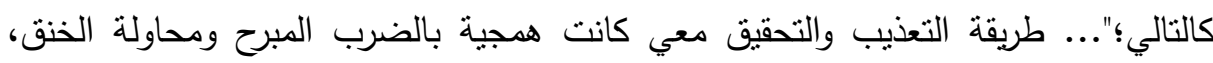
وهذه المرحلة من التعذيب قاسية جدا ومتوحشة لانها تهدف بالأساس الى كسر ارادة الاسير

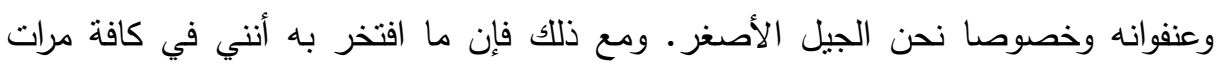

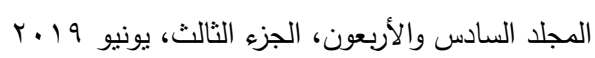


الاعتقال لم يستطيعوا انتزاع اعتراف مني عن أي شيء. وعلى كل حال، تلثئم الجروح وتتعافى عند انتهاء التحقيق وانتقال الأسير الى غرف السجن والانخراط مع المعتقلين الآخرين

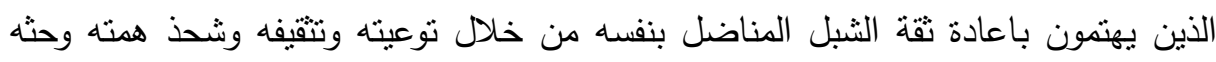

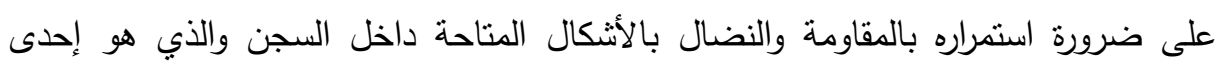

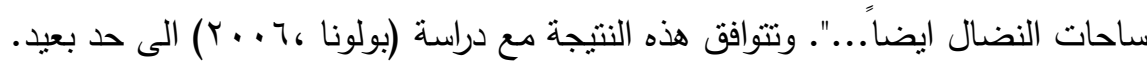

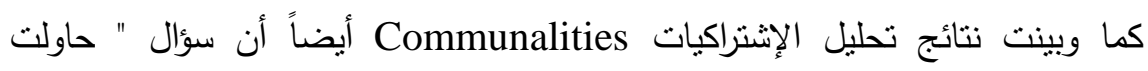

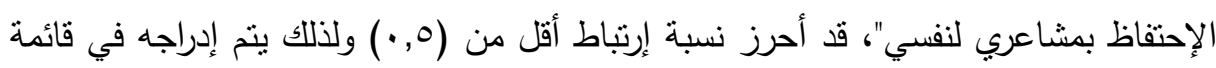

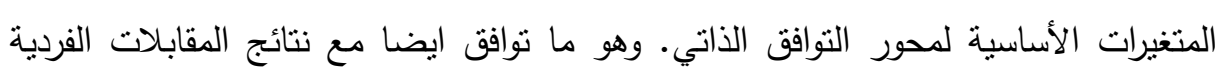

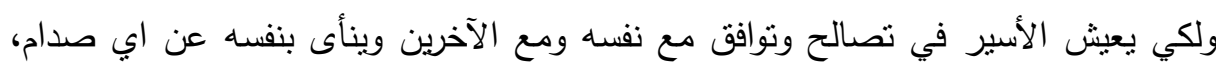

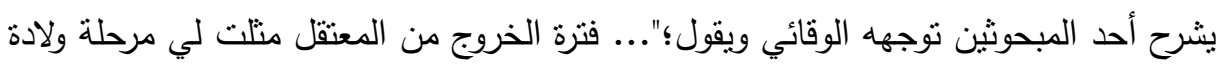

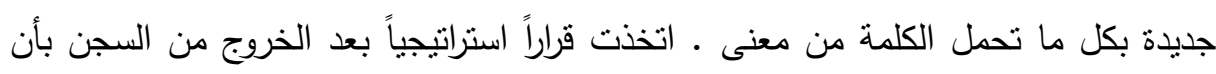

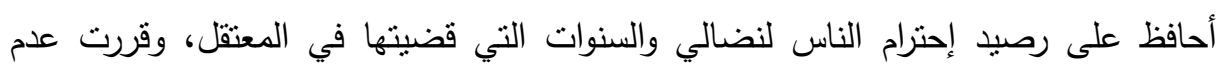
التدخل في خلافات أو تتاقضات، فأنا أقف على الحياد، وفي منطقة الوسط بين كل

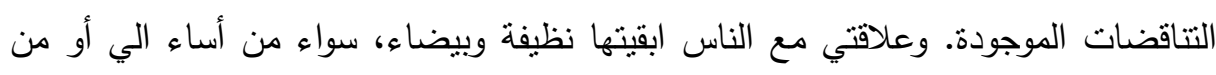
ومن خلال إجابة إحدى الأسيرات بكلام مؤثر وقوي وإيجابي عن مشاعرها يظهر مدى

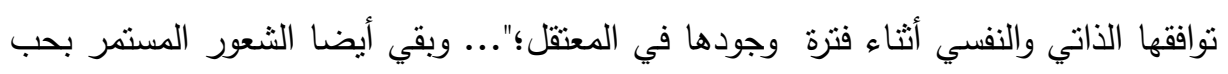
الحياة وتكوين اسرة واطفال والذي أجّجه ولادة احدى الاسيرات داخل المعتقل وتتاوب الاسيرات

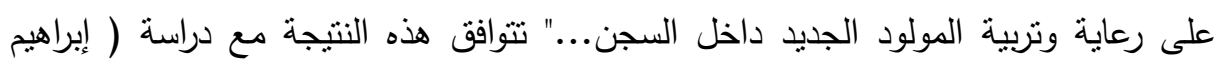

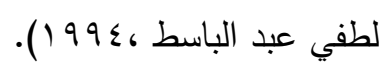

\section{المجرويامي}

ا ـ ضرورة دعم وإسناد الأسرى وحثهم لإستكمال برامج التوعية والتثقيف والجلسات التنظيمية

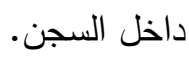

r. وضع برامج تأهيل للأسرى يمكن لها أن تلبي إحتياجات ومتطلبات الأسرى العديدة. 
r. وضع برامج توعية وتثقيف لجيل المراهقة من الاسرى المحررين وحتى الأسرة نفسها في سبيل دعم وشحن الروح الوطنية عندهم وقطع الطريق على الاحتلال الذي يحاول إصطياد

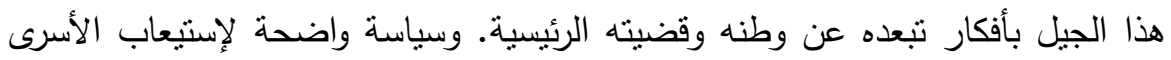
في العمل داخل مؤسسات الدولة المدنية والأمنية. ـ ـ إعطاء أولوية للأسرى المحررين للعمل في الوظائف الرسمية بعد تأهيلهم وإستيفائهم شروط شغل هذه الوظائف. ه. دمج أسر الأسرى المعتقلين في مؤسسات تمكنهم من التعليم والعمل لاحقا في وظائف تلبي لهم حياة كريمة. 7. نوفير تأمين صحي شامل للمعتقلين المحرين وأسرهم يمكنهم من علاج الأمراض سواء الجسدية أو النفسية التي سببها فترة اعتقال الأسير. V. فتح أندية ومراكز شبابية تقدم خدمات وانشطة تمكن المعتقلين المحررين واسرهم من شغل فئل

$$
\text { وقتهم في مراكز لها انشطة وخدمات هادفة. }
$$

^. دعم المؤسسات التي تعنى بتقديم المشاريع الصغيرة والمتوسطة للأسر المحتاجة أو التي هاتي

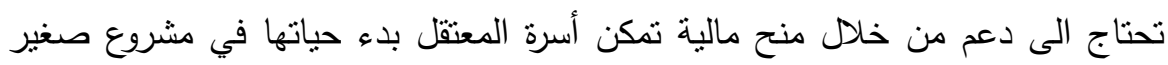
منل ( مشروع خياطة، تطريز ، زراعة .....الخ).

وفي الختام نقول أن هذا البحث قد أظهر بأنه على الرغم من بشاعة نداعه ورحشية المحتل

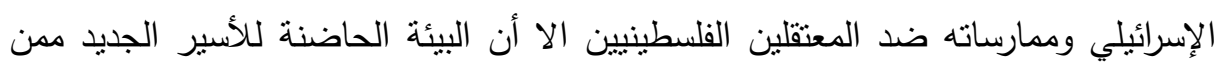

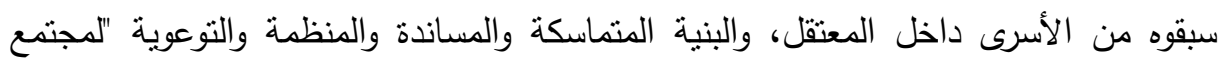

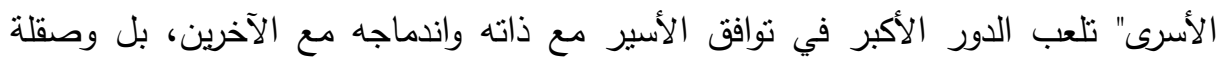

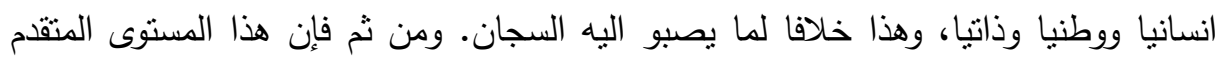

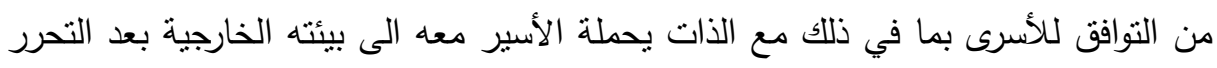

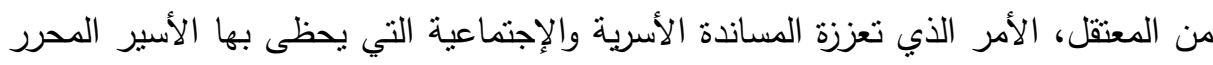

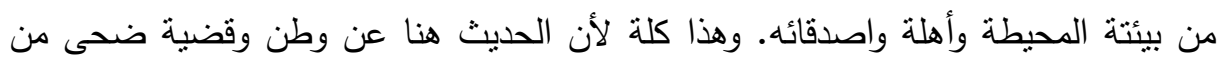

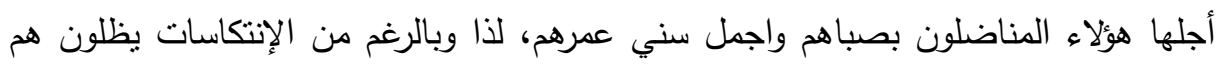

$$
\text { المجلد السادس والأربعون، الجزء الثالث، يونيو } 9 \text { بـ }
$$


أيقونة النضال وشعلته التي لا تخبو والتي يلتق حولها ويمجدها الجميع وأن كبا البعض أحيانا.

\section{2ant}

إبراهيم لطفي عبد الباسط:"عمليات تحمل الضغوط في علاقتها بعدد من المتغيرات النفسية

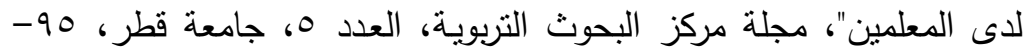

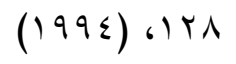

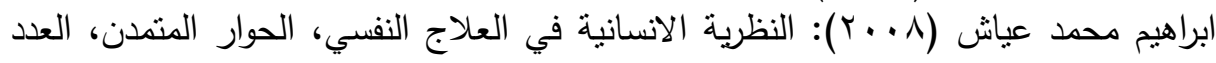

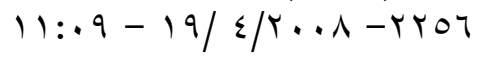

أميرة عبد العزيز الديب (•99 (19): سيكولوجية التوافق النفسي في الطفولة المبكرة، مكتبة دار

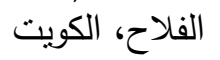

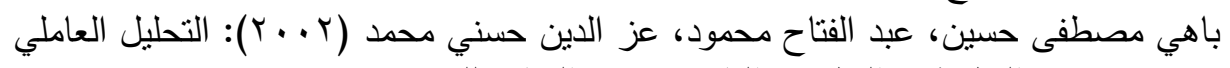

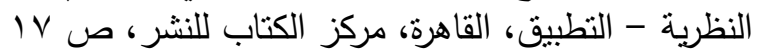

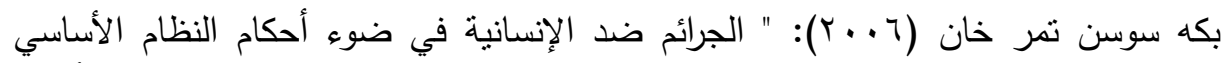

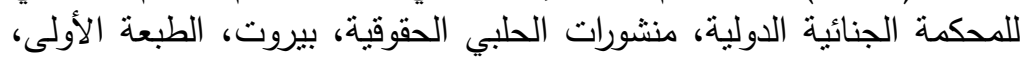

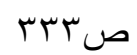

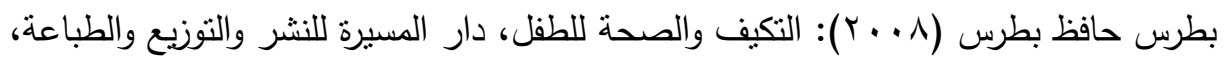

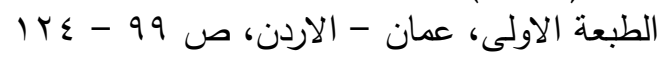

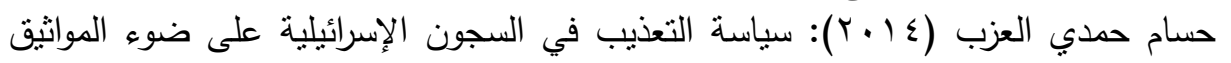
الدولية، مركز راثنيل كوري الفلسطيني لحقوق الإنسان ومثابعة العدالة الدولية،

غزة

حسن أحمد محمد حميدة (Y r ب):" العلاقة بين أحداث الحياة الضاغطة ومستوى التوافق

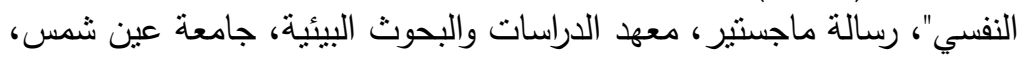

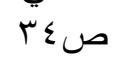

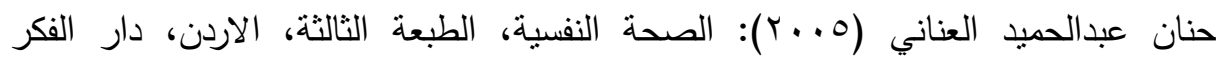
للطباعة والنشر النشاني

سابا، رغدة، والسراج، إياد (1991) (199): طرق التعذيب وآثاره النفسية، جمعية فلسطين الدولية

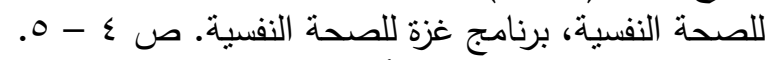

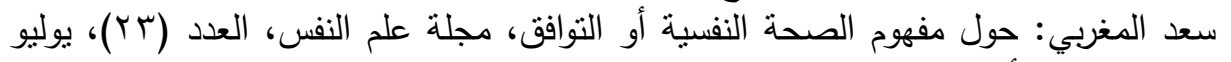
أغسطس سبتمبر (991 19 ، الهيئة المصرية العامة للكتاب، القاهرة. 


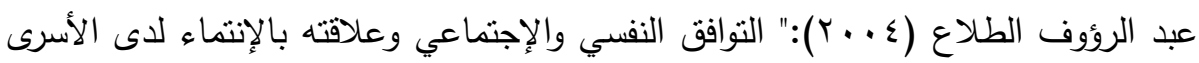

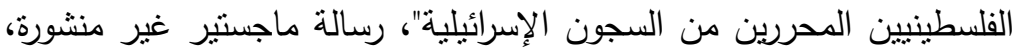

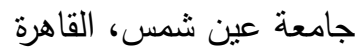

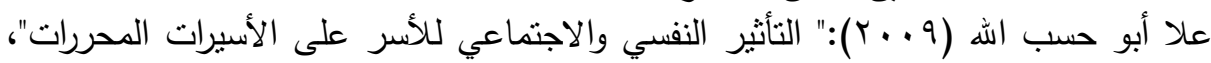

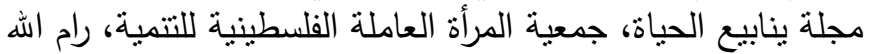

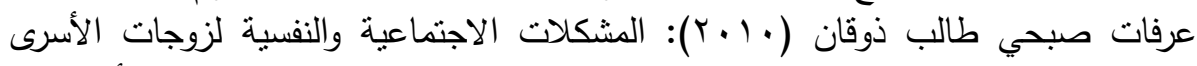

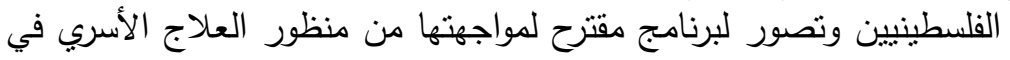
خدمة الفرد، رسالة ماجستير غير منشورة، كلية الخدمة الاجتماعية، جامعة العاجية حلوان

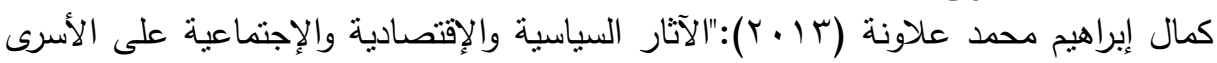

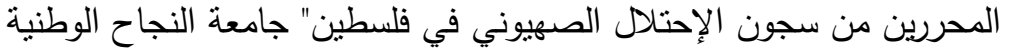

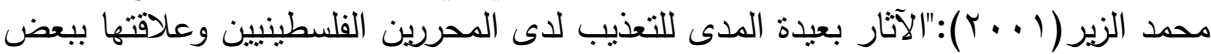

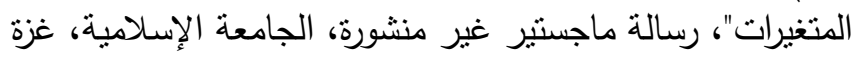

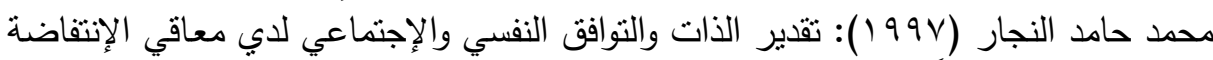

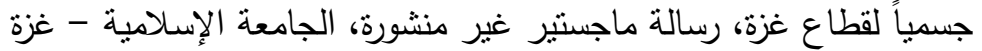

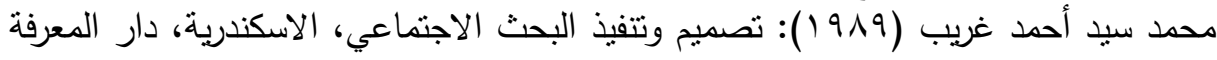

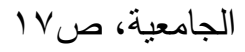

مدحت عبد الحميد (·99 (19): لصحة النفسية والتوافق الدراسي، دار المعرفة الجامعية، القاهرة، r. ص

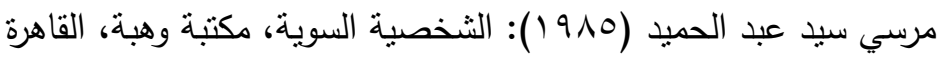

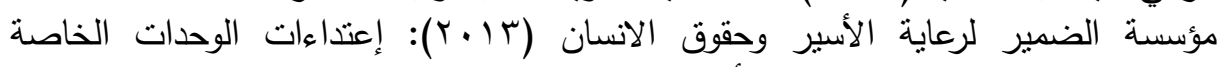

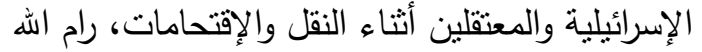

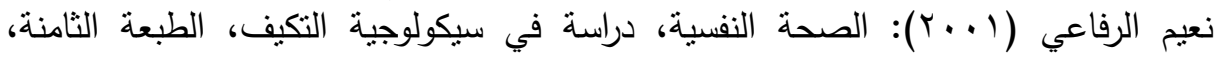

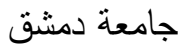
هلال أبو فراس (9 . . r): معاناة الأسير الفلسطيني في سجون الاحتلال الاسرائيلي، الطبعة

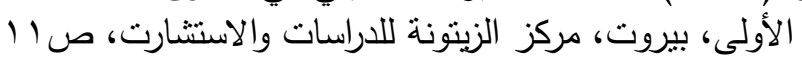

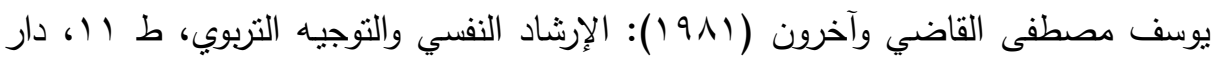

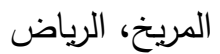
سماره عزيز ونمر عصام (1991()): محاضرات في التوجيه والإرشاد النفسي، دار الفكر العربي للتوزيع والنشر ، الأردن

Blonna, R. (2006): "Coping With Stress in a Changing Word", McGrawHill- Companies,4ED,Isbn: 9780073026602,p432.

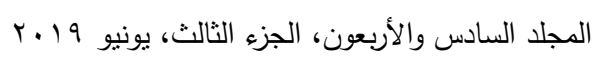


Borella, N.: A Study of Social Support Network Measurement in high school students. Japanese Journal of health psychology. Vol. (7). No. (1) , (1999).

Fichten, G. S. et. al, (1989): College Students with physical disabilities: Myths and Realitites, Rehabilitaion psychology 34.4.234 257

http://kandouci.africa-web.org/rrsuite.htm

http://psychclassic.yorku.ca/spearman/chap1-4htm//chapter2

John hickman(2008): "What is a Prisoner of War For?" "Scientia Militaria". Vol. 36,No.2.

Koubekova, E. (2000): Personal and social adjustment of physically handicapped pubescent psycho logia Dietata, J. 35(1), pp. 32-39.

Maslow, A. H. (1970): Motivation and personality, (2nd ed.) Harprer \& Row, NY.

Ojeda, A. (2009): What is the psychological torture, (30/6/2016). Center for the study of Human Rights in the Americas. www.inguistics.ucdavis.edu/People/Fzojeda/humanrights/what_is_pt.pdf

Pellrtteri (2002): Self Concept and Self- Esteem in Elementary Children. Psychology in the Schools. 31,164- 171.

Segal, H. A.: Initial Psychiatric Finding of Recently Repatriated Pows. American Journal of Psychiatry. Vol. 111, 358:363, (1973).

Turner, S. and Gorst-Unsworth, C.: Psychological Sequelae of Torture, Medical Foundation Series (1/2/2016). www.torturecare.org.uk, (1993).

Zahava - Solomon, Karni-Ginzbury et. al, (1998): Coping with War Capitivity: The Role of Attachment Style. European Journal. 
مجلة العلوم البيئية

معهد الدراسات والبحوث البيئية - جامعة عين شمس لينان

\title{
SELF-COMPLIANCE OF PALESTINIAN PRISONERS RELEASED FROM ISRAELI PRISONS
}

\author{
Moaen Ansawy ${ }^{(1)}$; Ahmed M. El-Atik ${ }^{(2)}$; Mostafa I. Awad ${ }^{(2)}$ \\ and Isha Alrifai ${ }^{(3)}$
}

1) Post Grad. Institute of Environmental Studies and Research, Ain Shams University 2) Institute of Environmental Studies and Research, Ain Shams University 3) Education Sciences Faculty and Ramallah Women Training Centre, UNRWA, Palestine

\begin{abstract}
This article presents the findings of our research on mechanisms of self-compliance of the Palestinian prisoners released from Israeli jails after having completed their sentence. This is in connection to their personality traits and pertinent areas of compatibility.

Demographic data were collected on the released Palestinian prisoners in terms of (age, gender, marital status and number of family members). This is in addition to; socio-economic data (occupational status, level of education, income and standard of living), and behavioral data focusing on the psychological and social problems prisoners endure as consequences of deficits in adaptation to prison life. Mechanisms of compatibility and self-reconcilement that the prisoner resort to in order to overcome the psychological and social problems that he/she faced are explored. The self-compliance scale was used and demographic data were generated, including; age at arrest, age at discharge, number of arrests, current age, educational level, sex, social status and employment status.

The results showed that the consistent indicators and aspects in the self-compliance scale after the analysis were: Stand solid in order to overcome the effects of the experience of families and start beyond; I realized that I had brought myself a problem entering prison; I tried to keep my feelings to myself; I began to feel that the experience of prison
\end{abstract}

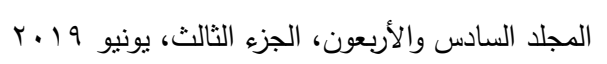


and after made me stronger than I was in the past; The first few days after liberation I lived in deep concern about the possibility of being rearrested.

Given the scale of self-compliance and comparison with statistically significant relationships in the analysis of variance (ANOVA), the extent of data consistency at the analytical levels, i.e., ANOVA and Factor Analysis, is shown. Most of the axes that emerged in the statistically significant relations at the first analytical level (ANOVA) reappeared at the second (Factor Analysis) analytical level. These include; being arrested at the age of early youth or adolescence, having spent many years in Israeli detention jails, and coming from different geographical areas and different political affiliations. However, given their young age on arrest, respondents had not yet formed their political identity but were rather urged to resist the sense of injustice, oppression and humiliation inflicted upon them by the occupier who broke into their villages and towns destroying properties and killing people. The irony is that while the occupation was imprisoning them to break the resistance before it becomes more and more entrenched with age, the prison provided them with an exceptional space for reading, learning and understanding the nature of the occupation and the motives of the Zionist movement, and increased their belief in the need to continue the struggle against the occupation including inside the prison itself, many of whom considered a battleground against the occupation.

It was also found that the self-compliance concept and its elements obtained a considerable share in the vocabulary, areas and forms of expression among the respondents so that most of their answers included formulas that have a meaning that was sometimes identical to the concept defined parameters, such as, "I began to feel that the experience of imprisonment and beyond made me stronger than I was in the past" and "I had some imaginative perceptions and aspirations for the reality of post-liberation." However, the majority of respondents were able to achieve self-compliance after liberation by "Standing firm in order to overcome the effects of the experience of imprisonment and the launch of the aftermath" and "trying to keep emotions solely to own self and not to reflect on behavior" and "I began to feel that the

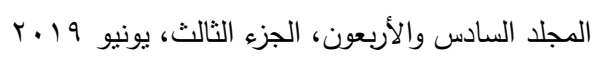


experience of imprisonment and beyond made me stronger than I was before ".

Released from captivity was a fundamental challenge for almost all liberated prisoners, as it brought them to the realization that they had to deal with new realities in all matters and at all levels. This includes a mindset that is compatible with what is achievable, far from the "the Republic of Plato" which governs the relations and behavior of the prisoners inside the prison.

In conclusion, this research shows that despite the brutality of the Israeli occupation and its practices against Palestinian prisoners, the embracing environment of the new prisoners by those who preceded them, and the cohesive, supportive, organized and awareness-based structure of the "prisoners' community" plays the major role in the prisoner's sefl-compliance and his/her integration with others, as well as his/her human, national and self-sufficiency, and this is contrary to what the jailer wants. Thus, this advanced level of compatibility of and among the prisoners, including with one's own self, the prisoner carries to his/her external environment after liberation from prison, where it is strengthened by the family and social support enjoyed by the liberated prisoner from his/her surrounding environment and his family and friends. This is because the talk here is about a homeland and a Cause for whom these freedom fighters scarified the most beautiful and productive years of their lives. So despite the setbacks, they remain the "Icon of the Struggle" and its flame that continue to be glorified by all, even if some relapse at times. 